BOOYSEN F LE R, VAN RENSBURG HCJ, BACHMANN M,

LOUWAGIE G and FAIRALL L

\title{
THE HEART IN HAART: QUALITY OF LIFE OF PATIENTS \\ ENROLLED IN THE PUBLIC SECTOR ANTIRETROVIRAL \\ TREATMENT PROGRAMME IN THE FREE STATE \\ PROVINCE OF SOUTH AFRICA
}

(Accepted 21 April 2006)

\begin{abstract}
This paper reports on the quality of life of patients enrolled in the public sector antiretroviral treatment programme in the Free State province of South Africa. Statistical analysis of cross-sectional data reveals that it is not access to treatment per se that enhances the quality of life of those who have come forward for ART. Rather, it is the health benefits associated with treatment, levels of stigmatisation, quality health care services, and the ability of persons to access support and care, both from within and outside the health care sector, that are independently associated with improvements in and differences in levels of quality of life.
\end{abstract}

KEY WORDS: antiretroviral treatment, happiness, HIV/AIDS, life satisfaction, South Africa

\section{BACKGROUND}

Just a few years ago, the possibility of expanding highly active antiretroviral treatment (HAART) to the general population in developing countries seemed slim, given that from an economic point of view it was considered unaffordable, particularly in sub-Saharan Africa (Forsythe and Gilks, 1999; Wood et al., 2000). ${ }^{1}$ In addition, there initially was some scepticism about the clinical effectiveness and biomedical benefits of antiretroviral treatment (ART). Yet, in but a few years time, the world has seen the picture change as political, moral and legal pressures have seen the price of both patent and especially of generic antiretroviral drugs (ARVs) declining substantially and financial and technical resources being mobilised on a global scale in order to make access to ART a reality. Key in this was the establishment of the Global Fund to Fight AIDS, Tuberculosis and Malaria, PEPFAR and WHO's $3 \times 5$ initiative, as well as agreements reached at Doha 2001 on 
TRIPS and public health issues (Coetzee et al., 2004; Ijumba et al., 2004). Economic evaluations, moreover, now concur that ART presents a costeffective response to the HIV/AIDS epidemic compared to alternative responses such as hospitalisation and treatment with single or dual ART regimens (Sendi et al., 1999; Moore, 2000; Freedberg et al., 2001; Miners et al., 2001; Cleary et al., 2004; Teixeira et al., 2004). Antiretroviral treatment also stands to benefit society and the economy at large, given the resultant increase in life expectancy (Dorrington et al., 2004) and gains in productivity resulting not only from the treatment of infected individuals, but also from changes in time utilisation by caregivers (Sendi et al., 2004). Between November 2003 and June 2005, the estimated number of people on treatment has increased from approximately 400,000-970,000. Estimated coverage of ART in Sub-Saharan Africa over this period increased from 2 to $11 \%$, with an estimated half million AIDS sufferers receiving ART by June 2005 (WHO, 2005).

South Africa faces one of the highest HIV prevalence rates in the world 2004 estimates of HIV prevalence among the total population range between 8.2 and $12.9 \%$ or $3.8-5.6$ million infected persons (Dorrington et al., 2004). Until recently, however, only some people enjoyed access to ART. By 2001, for example, almost three quarters of options offered by private medical schemes in South Africa provided access to antiretroviral therapy, which covers $92 \%$ of beneficiaries of medical schemes (Stein et al., 2002). Yet, only an estimated $15.7 \%$ of the population had access to medical insurance (Council for Medical Schemes, 2003). Since that time there has been a shift towards providing universal access to ART, driven as well by political and legal pressures exerted on government, in particular by the likes of the Treatment Action Campaign (TAC). ART was recently added to the list of prescribed minimum benefits that all public hospitals and other designated service providers are by law required to provide according to specified clinical protocols and criteria. ${ }^{2}$ Access to free ART also became a reality in the public health care sector in 2003.

The South African public sector antiretroviral treatment programme is a predominantly non-physician driven model of care. Patients are screened (voluntary counselling and testing) and staged (CD4 and clinical) by nurse practitioners in primary care clinics (assessment sites). Patient who qualify for treatment (i.e. those with CD4 counts $\leq 200$ and/or WHO AIDS stage 4) are then referred to a nearby hospital (treatment site). Here a physician assesses the individual in order to confirm that the patient fulfils the criteria for treatment and to exclude any reason for delaying treatment (e.g. untreated tuberculosis). Patients are then referred back to the assessment site 
for drug readiness training (DRT), a programme lasting 3 weeks. During DRT patients attend weekly modules on disclosure, positive living and antiretroviral treatment. Attendance by DRT of a treatment supporter or 'treatment buddy', preferably one chosen by the patient, is encouraged. On completion of DRT, patients return to the physician for clinical review and initiation of treatment. Monthly follow-up of the patient is based at the assessment site and nurses are responsible for the distribution of drugs dispensed by the hospital pharmacy, the drawing of blood (physicians monitor viral loads, CD4 count and other clinical results), and monitoring and promotion of adherence. Except for the first three months after initiation of ART, when physicians review the progress of patients on a monthly basis, patients are assessed clinically on a six-monthly basis (National Department of Health, 2003, 2004).

Public access to ART, however, is not as yet universal. Treatment is being phased in over a 5-year period (2003-2007), the aim being to achieve universal access by 2007 (National Department of Health, 2003). The Free State province in 2003 was home to an estimated 29,310 of the total 388,701 new AIDS cases that would qualify for public sector ART. It was estimated that a further 35 to 46 thousand persons in the province would qualify for ART annually compared to 463 to 625 thousand nationally (National Department of Health, 2003). By April 2005, a total of 1496 patients had started taking ARVs in the Free State province (this figure rose to 3322 by October 2005), while approximately 50,000 people had started ART nationally (Stewart and Loveday, 2005; Free State Department of Health, 2006).

One of the primary goals of ART is to improve the health-related quality of life (HRQOL) of patients with AIDS and indeed this has been documented in numerous studies (Eriksson et al., 2000; Carrieri et al., 2003; Burgoyne and Renwick, 2004; Hughes et al., 2004; Teixeira et al., 2004; Tramarin et al., 2004). Nonetheless, a few studies have reported small or insignificant gains in health-related quality of life, while others have reported declines in health-related quality of life as a result of drug side effects (Brecht et al., 2001; Murri et al., 2003).

If however one takes the perspective that AIDS is more than simply a physical disease or medical condition, as is the case in social epidemiology (Poundstone et al., 2004), then treatment should benefit patients not only in respect of their health (or HRQOL), but their general quality of life (QOL). In other words, the "ultimate goal [of treatment should be to] maintain and enhance the scope, depth and intensity of human well-being or happiness" (Hajiran, 2006, p. 33). The Operational Plan for the Comprehensive HIV and 
AIDS Care, Management and Treatment moreover states that a primary goal of the ART programme is "improvements in quality of life" (National Department of Health, 2003, p. 62) - it does not say 'health-related' quality of life. Few studies however have attempted to assess the impact of ART on quality of life. ${ }^{3}$ The one objective of this paper is to report on the quality of life of patients accessing public sector ART services in the Free State province of South Africa. A second objective is to identify those factors associated with higher levels of and improvements in the quality of life of individuals receiving ARVs.

\section{DATA}

The Ethics committee of the Faculty of Humanities (UFS) approved the study protocol. Study participants were sampled randomly from a list of patients who had qualified for ART in each district during the first two months of the programme. ${ }^{4}$ Treatment patients represent those patients who had commenced treatment by the end of this 2-month period, non-treatment patients those who had been found eligible for treatment, but had not yet started taking antiretroviral drugs (ARVs), primarily because a lack of resources and problems with drug supplies limited the capacity of the health services to immediately put all eligible patients on treatment. The distinction between treatment and non-treatment cases is needed to assess the impact of treatment on select health, social, behavioural and economic outcomes in this group of patients, who will be followed up periodically over the next 3-to 4-year period. ${ }^{5}$ For each of the five health districts, eighty patients were sampled randomly from these lists proportional to the number of treatment and non-treatment patients at each health care facility in the district. In cases where the list included fewer than 80 patients, as in Xhariep district, a census of all treatment and non-treatment cases was conducted. Trained enumerators conducted structured, face-to-face interviews with 371 study participants (Table I). ${ }^{6}$ Written, informed consent was obtained from study participants by the nursing personnel at the respective clinics, as well as by the enumerator.

The sample population can be described as follows: almost two thirds of respondents are female. The average age was 37.5 years, while the households to which these persons belonged on average included four household members. Although half of respondents were married at the time, a relatively large number of these respondents (76 of 186) did not live with their spouses/partners. As one would expect in a public sector health care programme, the respondents can in certain respects be described as relatively 
TABLE I

Composition of sample, by treatment status and district

\begin{tabular}{|c|c|c|c|c|c|c|}
\hline \multirow[t]{2}{*}{ District } & \multicolumn{2}{|c|}{$\begin{array}{l}\text { Patients receiving } \\
\text { treatment }\end{array}$} & \multicolumn{2}{|c|}{$\begin{array}{l}\text { Patients awaiting } \\
\text { treatment }\end{array}$} & \multicolumn{2}{|l|}{ Total } \\
\hline & Sample $(n)$ & $\%$ & Sample $(n)$ & $\%$ & Sample $(n)$ & $\%$ \\
\hline Lejweleputswa & 55 & 67.9 & 26 & 32.1 & 81 & 21.8 \\
\hline Motheo & 58 & 71.6 & 23 & 28.4 & 81 & 21.8 \\
\hline Fezile Dabi & 76 & 90.5 & 8 & 9.5 & 84 & 22.6 \\
\hline Thabo Mofutsanyana & 64 & 79.0 & 17 & 21.0 & 81 & 21.8 \\
\hline Xhariep & 15 & 34.1 & 29 & 65.9 & 44 & 11.9 \\
\hline Total & 268 & 72.2 & 103 & 27.8 & 371 & 100.0 \\
\hline
\end{tabular}

poor. Only $14.5 \%$ (54) of respondents were employed at the time, half in the informal sector. Fifty-six percent of respondents (207) reported that they were the main breadwinners in their family. The unemployment rate (broad definition) in the sample population was a staggering $66.9 \%$. However, less than half of respondents participated in the labour market (43.6\%), with as many as 171 respondents $(45.7 \%)$ indicating that they were not able to work or look for work due to illness/disability. Only $2.9 \%$ of respondents (11) had access to medical aid. Just more than $80 \%$ (307) indicated their highest educational qualification as being grade 11 or lower, while $14.6 \%$ (54) completed their secondary education and 3.7\% (14) had some form of tertiary education.

Yet, the data also suggests that the respondents are not the poorest of the poor. Almost 70\% (258) of respondents lived in dwellings where they had access to a flush or chemical toilet, either in the dwelling or the yard. As many as $90 \%$ (336) of respondents lived in dwellings with access to piped water: either on site or in the dwelling. Almost three quarters of respondents (275) lived in formal dwellings as opposed to 20.3 (76) and 6.2\% (23) living in informal and traditional dwellings, respectively. Mean personal income amounted to R634, with half of respondents receiving a social welfare grant (in particular disability grants), which amounted to either R740 or R780 per month, depending on when the interview was conducted.

\section{METHODS}

The study employs two sets of quality of life measures. On the one hand, patients' responses to two standard five-point scaled items regarding overall 
life satisfaction and global happiness are employed as measures of the general level of quality of life. Similar response scales are used to assess quality of life on thirty specific and, following Møller (1998), ten main domains of life satisfaction. These items are identical to those included in surveys forming part of the South Africa Quality of Life Trends project (Møller and Schlemmer, 1983; Møller, 1999). ${ }^{7}$ Thus, we take here the approach to studies of subjective well-being (SWB) that Kim-Prieto et al. (2005) argue is based on so-called global assessments of QOL derived from survey data.

On the other hand, two other items are employed as measures of improvements in quality of life. Patients were asked, "Since you started taking ARV medication, how has the following changed? (1) your physical health, (2) your emotional well-being". The response scale included four options: 'improved', 'remained the same', 'deteriorated', or 'fluctuated'. These data were employed to code two binary variables (yes $=1$, no $=0$ ) that distinguish between patients whose physical health and emotional wellbeing had improved since joining the ART programme, as opposed to those patients whose health and well-being have not improved and either remained unchanged, fluctuated or declined.

The analysis proceeded in three steps. Firstly, the quality of life of study participants is described at the hand of the above indicators of levels of and improvements in quality of life. Secondly, differences in quality of life measures by treatment status and treatment duration are assessed using appropriate statistical tests. The literature suggests that patients normally respond clinically to antiretroviral treatment during the first two or three months of treatment (Lavalle et al., 2000; Weidle et al., 2002; Coetzee et al., 2004; Laurent et al., 2004). Hence, in the analysis of difference in quality of life by treatment duration, a distinction is drawn between patients awaiting treatment, patients who have been taking ARVs for less than 2 months ( $<60$ days), patients who have received treatment for 2-3 months $(60$ 90 days), and patients who have been taking ARVs for longer than 4 months $(90+$ days). The tools employed in the statistical analysis include $t-, \chi^{2}$ - and Fischer exact-tests as well as one-way analysis of variance (ANOVA), the choice of which depends on the nature of the variables employed in the particular comparison. Finally, econometric techniques are employed to investigate factors associated with improved quality of life, measured here using the above indicators. These regression models all took the following general form:

$$
\mathrm{QOL}_{i}=\alpha \mathrm{IC}_{i}+\gamma \mathrm{TE}_{i}+\delta \mathrm{SHC}_{i}+\eta \mathrm{OS}_{i}+\lambda \mathrm{D}_{i}+\varepsilon_{i}
$$


$\mathrm{QOL}_{i}$ represents the quality of life for individual $i . \mathrm{IC}_{i}$ represents a vector of individual- and household-level characteristics and $\mathrm{TE}_{i}$ a vector of variables representing the treatment- and related experiences of individual $i . \mathrm{SHC}_{i}$ represents a vector of variables representing care and support available to individual $i$ within the health care sector, while $\mathrm{OS}_{i}$ represents a vector of variables representing various types of care and support available to individual $i$ from outside the health care sector. $\mathrm{D}_{i}$ is a categorical variable indicating the health district where the patient accessed treatment, $\varepsilon_{i}$ the error term, and $\alpha, \gamma, \delta, \eta$ and $\lambda$ vectors of parameters for each of the respective vectors of independent variables, which are described below in more detail. A review of published studies on quality of life and HIV/AIDS (mainly pertaining to HRQOL rather than QOL it may be added) formed the basis for the selection of independent variables. $^{8}$

\subsection{Individual and Household Characteristics}

$\mathrm{IC}_{i}$, the vector of individual- and household-level characteristics, includes age, gender, marital status, level of education, employment status, and dwelling-type.

\subsection{Treatment- and Related Experiences of PLWA}

$\mathrm{TE}_{i}$ represent a vector of variables representing the treatment- and related experiences of individual $i$. These include the length of time study participants have known their HIV-positive status, the reason why the respondent wanted to be tested for HIV when first testing HIV-positive, access to treatment and treatment duration, health-related quality of life, being hospitalised since enrolling in the ART programme, self-reported adherence, and the presence of side effects associated with ART. Health-related quality of life is measured with the aid of EQ-5D, an internationally standardised, simple, descriptive 5-domain index of health status. ${ }^{9}$ Patients receiving ARVs report significantly higher levels of HRQOL compared to those awaiting treatment $(p<0.01)$. In addition, HRQOL is significantly and positively correlated with treatment duration in patients receiving ARVs $(p<0.10)$. For this reason, interaction terms of combinations of access to treatment, treatment duration and HRQOL are employed to investigate the association between QOL and ART. 
In addition, we include variables measuring aspects not only of disclosure, as is common in the reviewed literature, but also perceived stigmatisation, which is not so common in QOL studies focusing on HIV/AIDS. The stigma scale, represented as standardised $z$-scores, is derived from the yes/no responses to eight questions asking study participants whether their spouse/ partner, parents, family members, friends, community members or neighbours, employer and co-workers, or members of their church treat them differently because they have HIV/AIDS (IIC $=0.571$, factor correlation $=0.756, \alpha=0.914)$. The scale represents a measure of what AbadíaBarrero and Castro (2006) describe as "non-institutional discrimination", which encompasses "relations between individuals, within families and within communities". Stigma, which apart from health problems represents a major difficulty in the lives of people living with AIDS (PLWA) (Busza, 2001; Lau et al., 2003; Kalichman and Simbayi, 2004), may affect QOL negatively as it is accompanied by social isolation and exclusion and even verbal and physical abuse (Klein et al., 2002; Ogden and Nyblade, 2005). Disclosure in turn may either enhance QOL by availing HIV-positive people of care and support, or may result in a decline in QOL if accompanied by stigmatisation. Disclosure and stigma therefore are closely intertwined (Paxton, 2002; Klitzman et al., 2004; Ogden and Nyblade, 2005; Siegel and Schrimshaw, 2005). Here, the stigma scale is significantly correlated with disclosure: the scale is negatively correlated with the number of different types of persons/parties the patient disclosed to prior to drug readiness training, but positively with the number disclosed to during or after drug readiness training $(p<0.01)$. Hence, we also include an interaction term in the regression model that denotes the perceived stigmatisation reported by patients who had disclosed their HIV status prior to drug readiness training (DRT).

Reported quality of life may also be associated with the quality of health care services. Perceptions of the quality of health care services is measured here by means of a standardised scale derived from a total of 34 five-point response scale items in the questionnaire pertaining to the quality of services delivered during drug readiness training (DRT) and at assessment and treatment sites (IIC $=0.404$, factor correlation $=0.636$, $\alpha=0.958){ }^{10}$

\subsection{Access and Support Available from within the Health Care Sector}

Messeri et al. (2002) and Williams et al. (2005) are of the opinion that access to ancillary services may be particularly important in supporting frontline 
medical care provided to persons living with HIV and in enhancing the QOL of PLWA. $\mathrm{SHC}_{i}$ represents a vector of binary variables representing care and support available to individual $i$ within the health care sector, both directly related to the ART programme, but also to the broader health care sector. Included here are variables measuring access to food supplements and a community health care worker. ${ }^{11}$

\subsection{Access and Support Available from Outside the Health Care Sector}

$\mathrm{OS}_{i}$ is a vector of variables representing various types of care and support available to individual $i$ from outside the health care sector, including informal support from household members and other organisations. Included here are variables measuring access to a treatment buddy, an HIV/ AIDS support group, an emotional or physical caregiver, a traditional health care practitioner, and HIV/AIDS-related services provided by other organisations. $^{12}$

\subsection{Health Care District}

Finally, $\mathrm{D}_{i}$ is a categorical variable indicating the health district where the patient accessed treatment. This variable captures differences in QOL explained by unobserved differences between districts ${ }^{13}$.

These independent variables (including main domains of life satisfaction) can be argued to represent measures of all four so-called 'qualities of life' (Veenhoven, 2000). Schematically, these variables can be presented as follows using Veenhoven's suggested theoretical framework (Table II) ${ }^{14}$ Thus, QOL is here conceptualised in the widest possible sense.

Due to the data constraints, however, there are also independent variables omitted from the models. These include clinical information such as ART regimen, WHO AIDS stage, CD4 counts and viral loads, HIV status of spouse or partner, health maintenance or self care behaviours, sexual orientation, exposure to risk of HIV infection, route of transmission/infection, indices of stress and depression, and a personality scale.

Two different econometric techniques are employed in estimating the regression models. The assumption here is that both sets of QOL measures are alternative but highly correlated and mutually dependent QOL measures. ${ }^{15}$ As Hajiran (2006, p. 33) puts it, quality of life is the "product of the interaction between an individual's personality and the continuous episodes of life events". Life satisfaction and happiness scores are formed by 


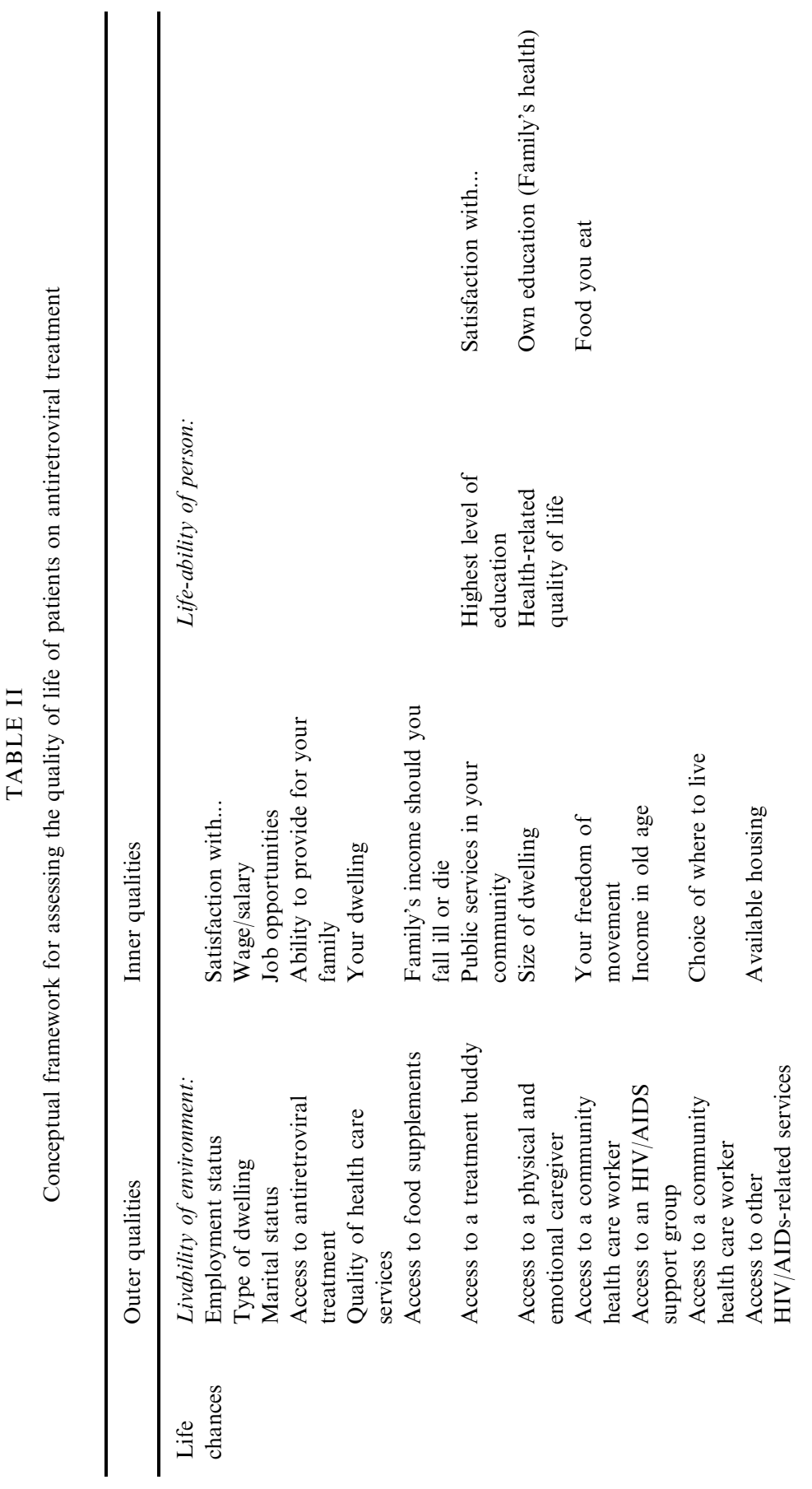




both personality and life events. This implies that these two QOL measures, as Kim-Pietro et al. (2005, p. 265) suggest, tap "a single construct with varying degrees of error, suggesting the existence of a single underlying... latent trait". Alexandrova $(2005$, p. 302$)$ describes this latent trait measured with the aid of life satisfaction and happiness scores as subjective well-being (SWB). Likewise, we consider improvements in physical and emotional wellbeing as mutually dependent. We employ simultaneous equation models to explore the factors associated with differences in levels of quality of life. These models each include two equations, one each for overall life satisfaction and global happiness, with the same set of independent variables regressed on the natural logarithm of each of the two endogenously determined quality of life scales. In the case of the two binary measures of quality of life, bivariate probit models are employed to explore the factors associated with improvements in physical and emotional well-being. Apart from continuous variables expressed in time (number of days), all continuous independent variables were transformed into logs to allow the coefficients to be interpreted as percentage changes.

Two sets of regression models are estimated for each set of QOL measures, one including data for all respondents ('aggregate models') and one including only those study participants receiving ARVs ('treatment models'). The first set of models is estimated to determine the factors associated with differences in the quality of life of patients eligible for and ready to commence ART. The second set of models is estimated to investigate the factors associated with differences in the quality of life of patients already on ARVs. With the exception of the measures of treatment duration, adherence and side effects of ART, which are included in the treatment models only, the aggregate models include all the above independent variables.

Two variants of these regression models are estimated, based on the so-called 'top-down' and 'bottom-up' approaches to quality of life studies. The 'top-down' approach assumes that respondents first reflect on overall quality of life and then decide how satisfied they are with specific life domains. Thus, global QOL measures are considered as independent assessments of quality of life that can be regressed on other indicators to explore those factors explaining differences in quality of life. The 'bottomup' approach takes the view that overall quality of life, as measured by responses to the two general items on overall life satisfaction and happiness, reflects the sum total of satisfaction on various life domains, which are measured by responses to individual items. This approach entails the regression of the satisfaction scores on the ten main life domains on the global QOL measures. Domain scores are therefore employed as additional 
independent variables in order to determine how satisfaction on different life domains contributes to overall quality of life (Michalos, 2004; Van Praag and Ferrer-I-Carbonell, 2004, p. 86). The regression models in all cases performed adequately in terms of overall fit $(p<0.01)$. The Wald $\chi^{2}$ statistic furthermore indicated that the bivariate probit models indeed are superior to separate probit models estimated for the two individual outcomes $(p<0.001)$.

\section{RESULTS}

Below, we first report on levels of quality of life, both in general as well as on specific and main domains of life, as well as changes in subjective well-being. Next, we investigate differences in quality of life by treatment status and duration. Lastly, we explore those factors associated with quality of life, including satisfaction on main life domains, as well as health-related quality of life, access to treatment, and a host of other personal- and householdlevel characteristics and treatment- and support-related characteristics of study participants.

\subsection{Quality of Life of Patients Ready to Commence ART}

The results show that patients selected for ART are relatively satisfied with their lives (Table III). More than three quarters of all patients are satisfied or very satisfied with their lives, with $8.9 \%$ only being dissatisfied with their lives.

Interestingly, however, a significantly smaller proportion of patients are happy with life in general compared to those who were satisfied with life in general $(p<0.01)$ (Table III). (This is also true for patients receiving ARVs and patients awaiting treatment). Just more than half of study participants are happy or very happy with their lives, while more than a third are very or fairly unhappy with their lives. However, these global QOL measures conceal considerable variability in satisfaction with different life domains.

The three main life domains with which patients are least satisfied are work, education, and income and social security (Figure 1). In particular, patients are very dissatisfied with the availability of job opportunities (work domain), as well as insurances against illness or death, their wage or salary, their ability to provide for their families, and income in old age (income and social security domain). Transport costs also featured as an item of particular dissatisfaction (Figure 2). The relative high importance of 
TABLE III

Self-reported quality of life, by treatment status

\begin{tabular}{lrrrrr}
\hline Indicator & $\begin{array}{l}\text { Patients } \\
\text { receiving } \\
\text { treatment }\end{array}$ & $\begin{array}{l}\text { Patients } \\
\text { awaiting } \\
\text { treatment }\end{array}$ & $\begin{array}{l}\text { All } \\
\text { patients }\end{array}$ & Sample $(n)$ & $p$-Value \\
& & & & & \\
\hline Overall life satisfaction (\%): & 2.6 & 5.9 & 3.5 & 13 & 0.173 \\
Very dissatisfied & 4.5 & 7.8 & 5.4 & 20 & \\
Dissatisfied & 15.4 & 11.8 & 14.4 & 53 & \\
Neither dissatisfied nor satisfied & 43.1 & 48.0 & 44.4 & 164 & \\
Satisfied & 34.5 & 26.5 & 32.3 & 119 & \\
Very satisfied & 100.0 & 100.0 & 100.0 & 369 & \\
Total & 77.5 & 74.5 & 76.6 & 369 & 0.270 \\
Satisfied or very satisfied (\%) & 4.5 & 3.9 & 4.3 & 16 & 0.001 \\
Global happiness (\%): & 29.5 & 37.9 & 31.8 & 118 & \\
Very unhappy & 8.6 & 6.8 & 8.1 & 30 & \\
Fairly unhappy & 39.9 & 48.5 & 42.3 & 157 & \\
Neither unhappy nor happy & 17.5 & 2.9 & 13.5 & 50 & \\
Fairly happy & 100.0 & 100.0 & 100.0 & 371 & \\
Very happy & 57.1 & 51.4 & 55.7 & 371 & 0.149 \\
Total & & & & & \\
Fairly or very happy (\%) & & & & \\
\hline
\end{tabular}

socio-economic issues mirrors the relative impoverished nature of the study population.

More than three quarters of patients are satisfied or very satisfied with their personal life, socio-political issues, and their family life (Figure 1). Underlying these high levels of satisfaction are particularly high scores on self-esteem, respect in the community, and spare time activities (all personal life domain), as well as satisfaction with voting rights and freedom of movement (all socio-political domain). In addition, in respect of the housing domain, respondents are highly satisfied with their choice of where to live (Figure 2).

In terms of improvements in subjective well-being, a very high proportion of study participants indicated that their physical and emotional well-being had improved since they joined the public sector ART programme (Table IV). A small proportion only of respondents reported that neither their physical nor their emotional well-being had improved. The question, however, is whether these QOL measures differ significantly by treatment status and by duration of treatment. 


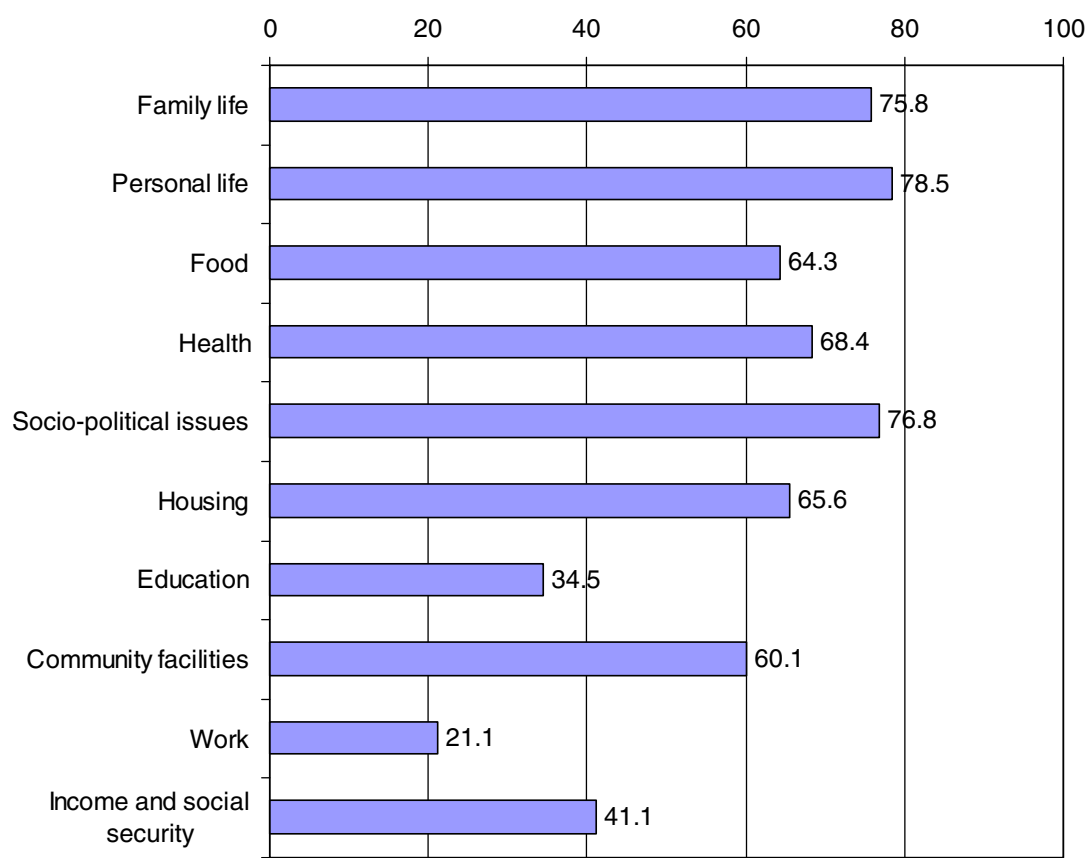

Fig. 1. Satisfaction (\%) on main life domains, total sample.

\subsection{Quality of Life, Access to Treatment and Treatment Duration}

The percentages of patients who are satisfied or happy with life in general do not differ significantly by treatment status, although satisfaction and happiness are slightly higher among those on ART compared to those awaiting treatment (Table III). The life satisfaction scale also does not exhibit any statistically significant differences by treatment status, but the global happiness scale does differ significantly by treatment status.

Significant increases in overall life satisfaction are only achieved at $90+$ days of ART (Figure 3). There are no significant differences in the life satisfaction score of patients awaiting treatment and those who have been taking ARVs for less than three months. Significantly higher happiness scores are reported, even at less than two months of treatment duration. Patients who have been taking ARVs for three months or longer also report significantly higher happiness scores than at baseline, but lower than at 1-2 months (Figure 4). Only patients who have benefited from the longerterm clinical benefits of ART report higher levels of life satisfaction. Happiness also is significantly higher at the 3-month plus treatment duration compared with patients awaiting treatment. 


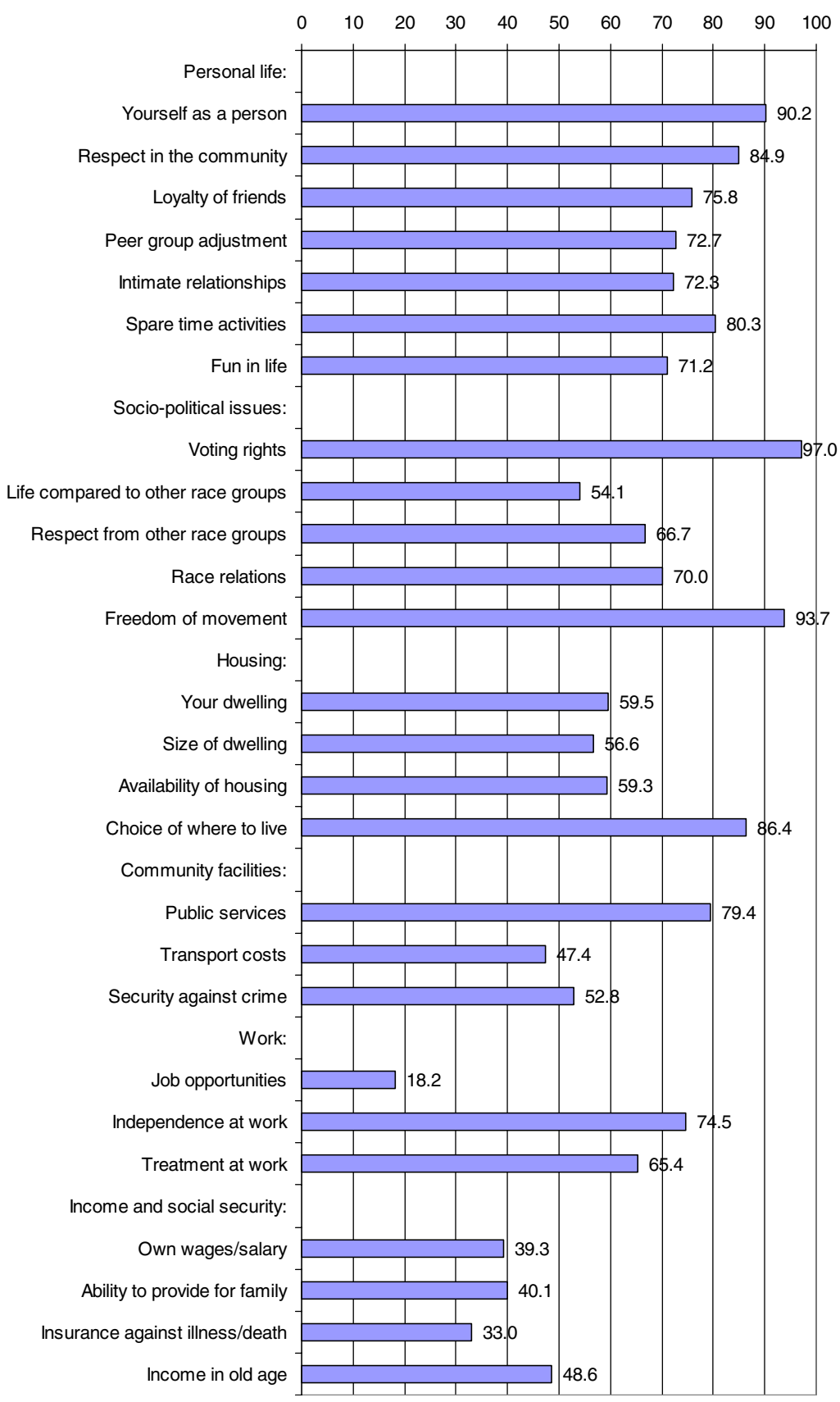

Fig. 2. Satisfaction (\%) on specific life domains, total sample. 


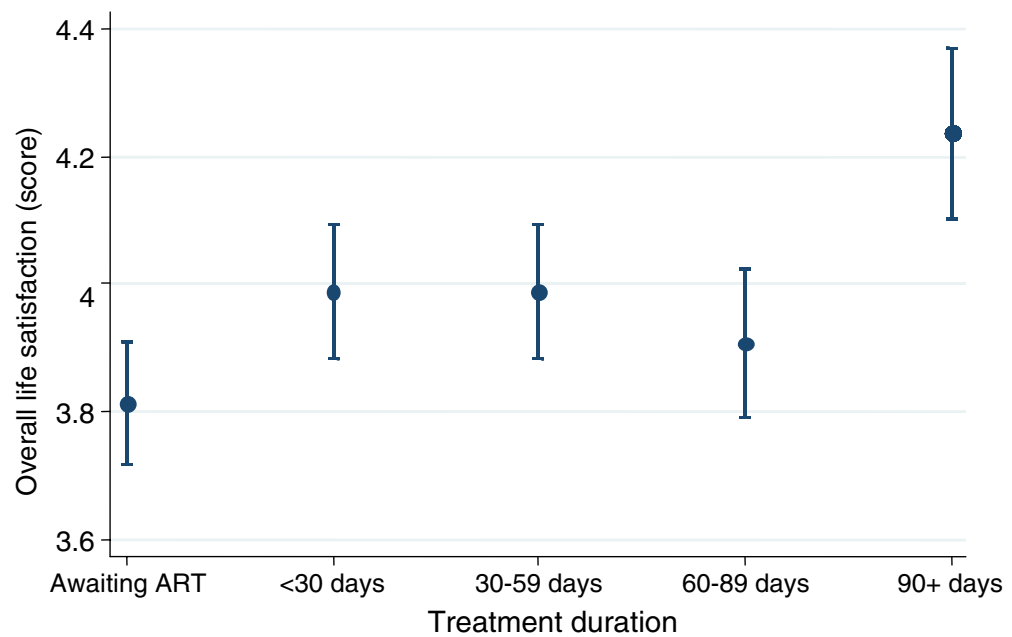

Fig. 3. Life satisfaction, by treatment duration.

Note: Bars represent means and standard errors of life satisfaction scores.

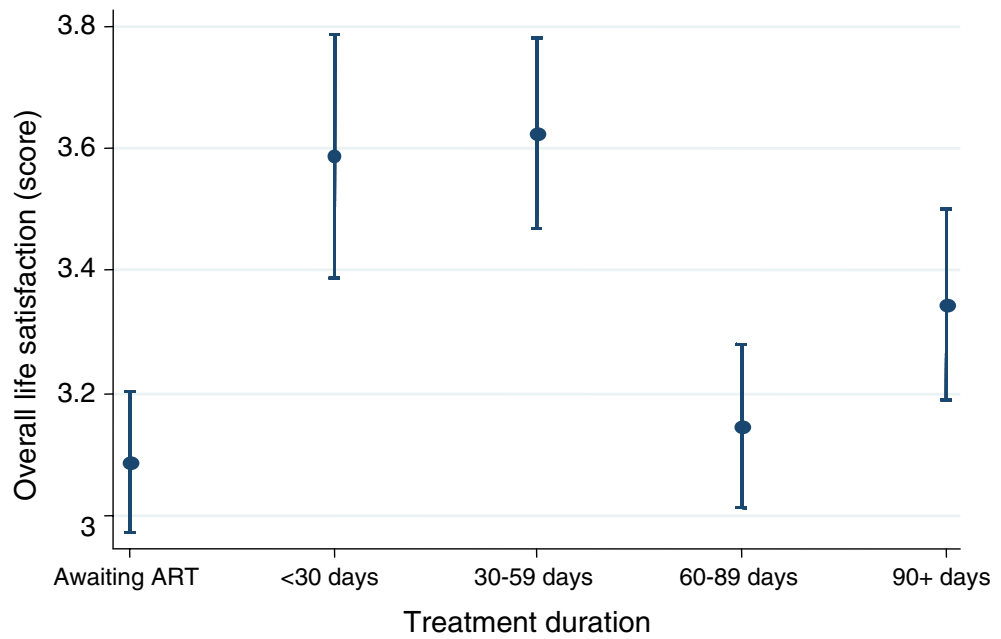

Fig. 4. Happiness, by treatment duration.

Note: Bars represent means and standard errors happiness scores.

On the one hand, patients receiving ART are significantly more satisfied compared with those awaiting ART in respect of their personal life and socio-political issues. Patients' on ARVs satisfaction with seven specific life domains also significantly exceed that reported by patients awaiting treatment, including satisfaction with self, peer group adjustment, fun in life (all 
TABLE IV

Self-reported change in physical health and emotional well-being since having completed drug readiness training, by treatment status

\begin{tabular}{lllllll}
\hline Indicator & $\begin{array}{l}\text { Patients } \\
\text { receiving } \\
\text { treatment }\end{array}$ & $\begin{array}{l}\text { Patients } \\
\text { awaiting } \\
\text { treatment }\end{array}$ & $\begin{array}{l}\text { All } \\
\text { patients }\end{array}$ & Sample $(n) p$-Value \\
& 86.1 & 55.3 & 77.5 & 370 & $<0.001$ \\
\hline $\begin{array}{l}\text { Physical health improved (\%) } \\
\text { Emotional well-being improved (\%) }\end{array}$ & 86.1 & 65.0 & 80.2 & 370 & $<0.001$ \\
$\begin{array}{l}\text { Neither physical health nor emotional } \\
\text { well-being improved (\%) }\end{array}$ & 7.4 & 31.0 & 14.0 & 370 & $<0.001$ \\
$\begin{array}{l}\text { Both physical health and emotional } \\
\text { well-being improved (\%) }\end{array}$ & 79.7 & 51.4 & 71.8 & 370 & $<0.001$ \\
\hline
\end{tabular}

personal life domain), life compared to other race groups (socio-political domain), and independence at work (work domain), (Table V). Satisfaction with spare time activities (personal life domain) and insurance against illness/death (income and social security domain) also differed significantly by treatment status, but only at the $10 \%$ level.

On the other hand, patients awaiting treatment are significantly more satisfied in respect of their own education compared with patients who

\section{TABLE V}

Significant differences in satisfaction on life domains $(\%)$, by treatment status

\begin{tabular}{llllll}
\hline Life domain & $\begin{array}{l}\text { Patients } \\
\text { receiving } \\
\text { treatment }\end{array}$ & $\begin{array}{l}\text { Patients } \\
\text { awaiting } \\
\text { treatment }\end{array}$ & $\begin{array}{l}\text { All } \\
\text { patients }\end{array}$ & Sample $(n)$ & $p$-Value \\
& & & & & \\
\hline $\begin{array}{l}\text { A. Main life domains } \\
\text { Personal life }\end{array}$ & 79.9 & 74.7 & 78.4 & 371 & 0.026 \\
Socio-political issues & 78.1 & 73.3 & 76.7 & 371 & 0.037 \\
Education & 31.8 & 41.5 & 34.5 & 368 & 0.039 \\
B. Specific life domains & & & & & \\
Yourself as a person & 92.1 & 85.2 & 90.2 & 369 & 0.023 \\
Loyalty of friends & 73.6 & 81.4 & 75.7 & 256 & 0.098 \\
Peer group adjustment & 75.3 & 65.6 & 72.7 & 363 & 0.032 \\
Spare time activities & 82.1 & 75.5 & 80.2 & 355 & 0.081 \\
Fun in life & 74.9 & 61.3 & 71.1 & 364 & 0.005 \\
Life compared to other race & 57.4 & 45.4 & 54.1 & 353 & 0.020 \\
groups & & & & & \\
Transport costs & 43.6 & 57.5 & 47.3 & 365 & 0.008 \\
Independence at work & 79.5 & 54.5 & 74.5 & 55 & 0.045 \\
Insurance against illness/death & 34.8 & 26.4 & 33.0 & 309 & 0.097 \\
\hline
\end{tabular}


commenced ART. For two items only, loyalty of friends (personal life domain) and transport costs (community facilities domain), did the satisfaction of those awaiting treatment with specific life domains exceed the satisfaction of those receiving ART (Table V).

Importantly, reported improvements in physical and emotional well-being are statistically significantly associated with access to treatment. Patients on ART are significantly more likely to have reported improvements in physical and emotional well-being compared with patients awaiting treatment (Table IV). Patients on ART are also significantly less likely to have reported no improvements in physical and emotional well-being since joining the ART programme (Figure 5).

The likelihood of having reported improved physical health rises significantly as treatment duration increases beyond zero, but levels off at higher levels of treatment duration. The same is true for improvements in emotional well-being. Although the likelihood of reporting improvements in emotional well-being declines significantly as treatment duration increases beyond three months, patients are still significantly more likely to have reported improvements in emotional well-being compared with patients awaiting treatment. The question, however, is how important access to treatment and more importantly treatment duration is when adjusting for other factors in attempting to explain differences in quality of life.

\subsection{Factors Associated with Differences in the Life Satisfaction and Happiness of Patients Ready to Commence ART}

Married respondents not cohabiting with their partners or spouses report significantly lower levels of life satisfaction and happiness compared with single respondents. Life satisfaction score reported by patients living in traditional dwellings are significantly lower compared with those living in formal dwellings. Patients in formal employment report significantly higher levels of happiness compared with those who are not employed. However, these associations are not statistically significant when adjusting for satisfaction on main life domains, except that is for marital status. In the full model, respondents who were married and lived with their partners or spouses reported significantly lower levels of overall life satisfaction compared with single persons. However, this association is relatively weak statistically (see Table VI).

In cases where the first HIV + test was prompted by illness rather than exposure to risk of infection and/or the routine/voluntary uptake of testing, patients are significantly less happy with life in general, even when adjusting 

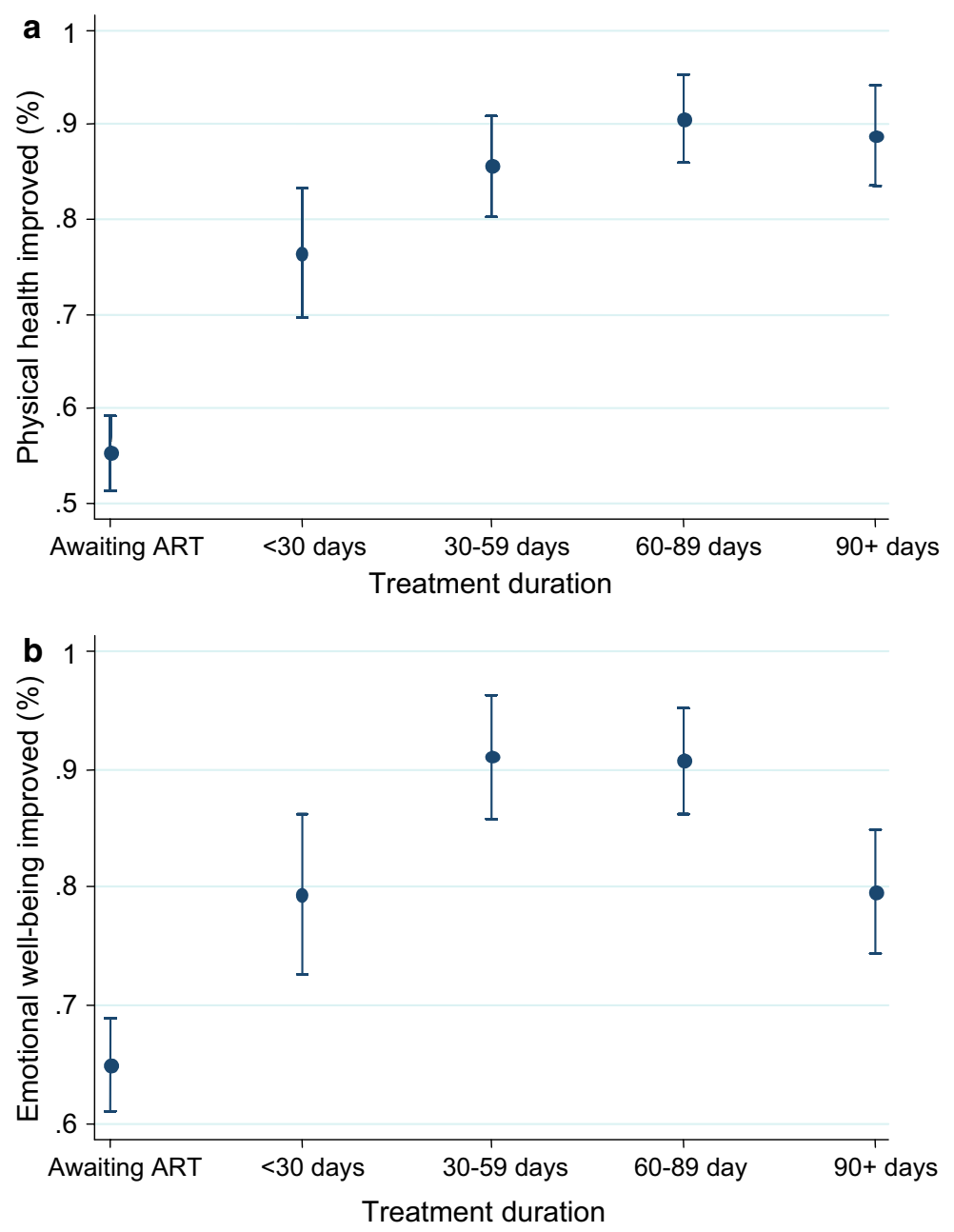

Fig. 5. Improvement in physical health and emotional well-being, by treatment duration. Note: Bars represent means and standard errors of the proportion of patients that reported an improvement in (a) physical health; (b) emotional well-being.

for differences in satisfaction on main life domains. Furthermore, patients who have commenced taking ARVs and who experienced improvements in HRQOL are significantly more satisfied with life. Patients who perceive less stigmatisation are significantly happier and more satisfied with life. Life satisfaction and happiness also increase significantly with the perceived quality of health care services provided at ART facilities. Yet, the 
THE HEART IN HAART

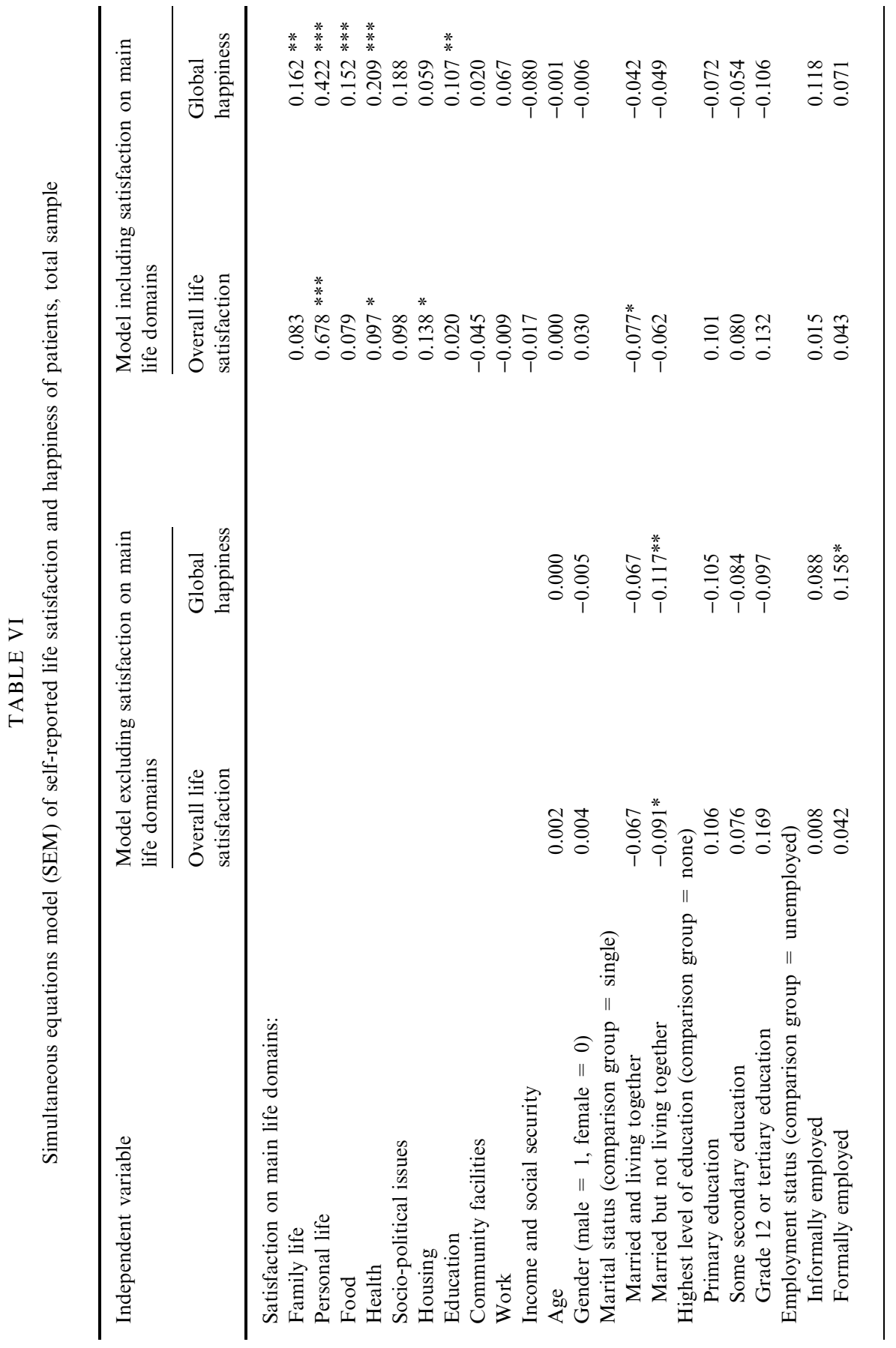




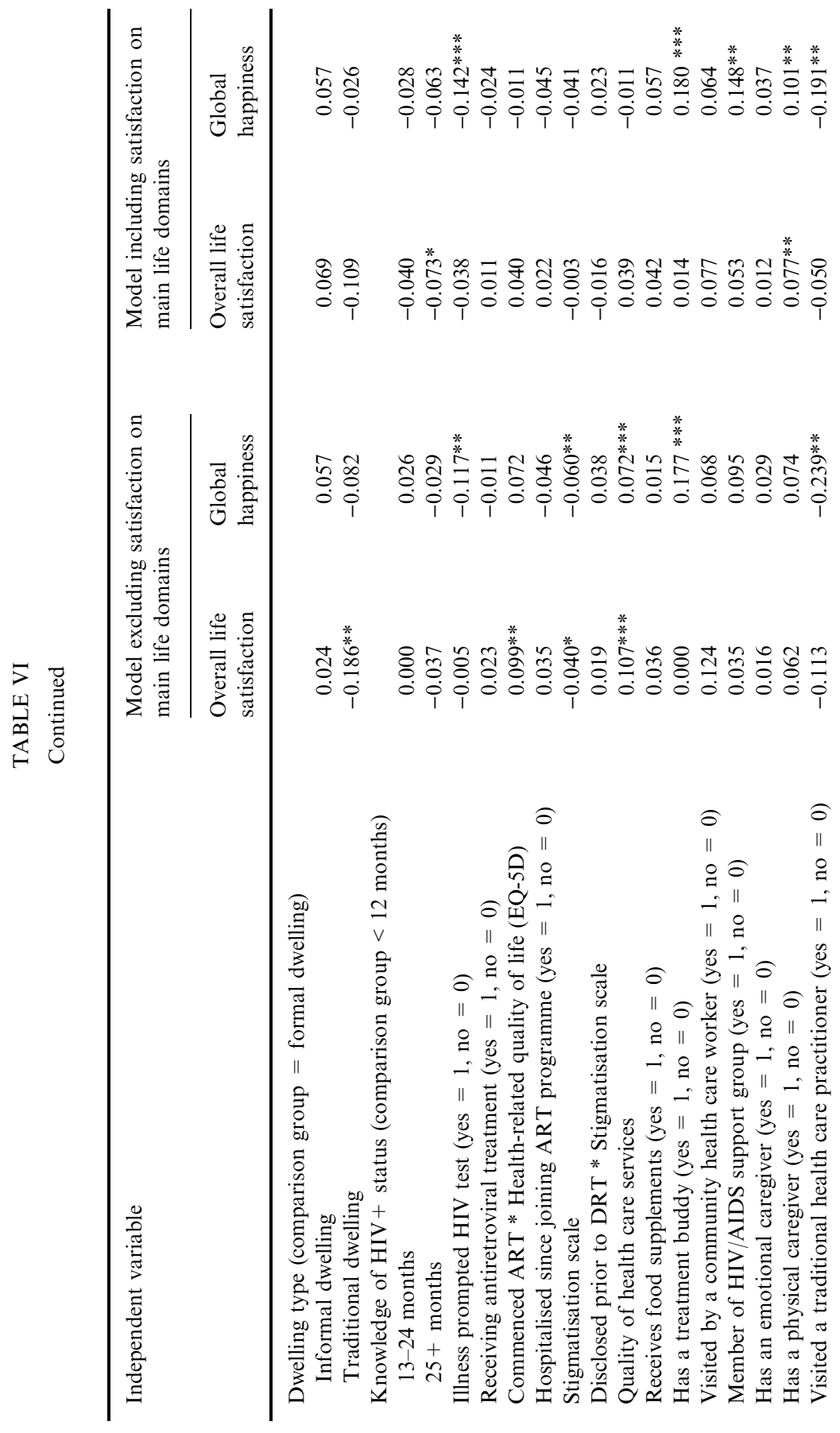




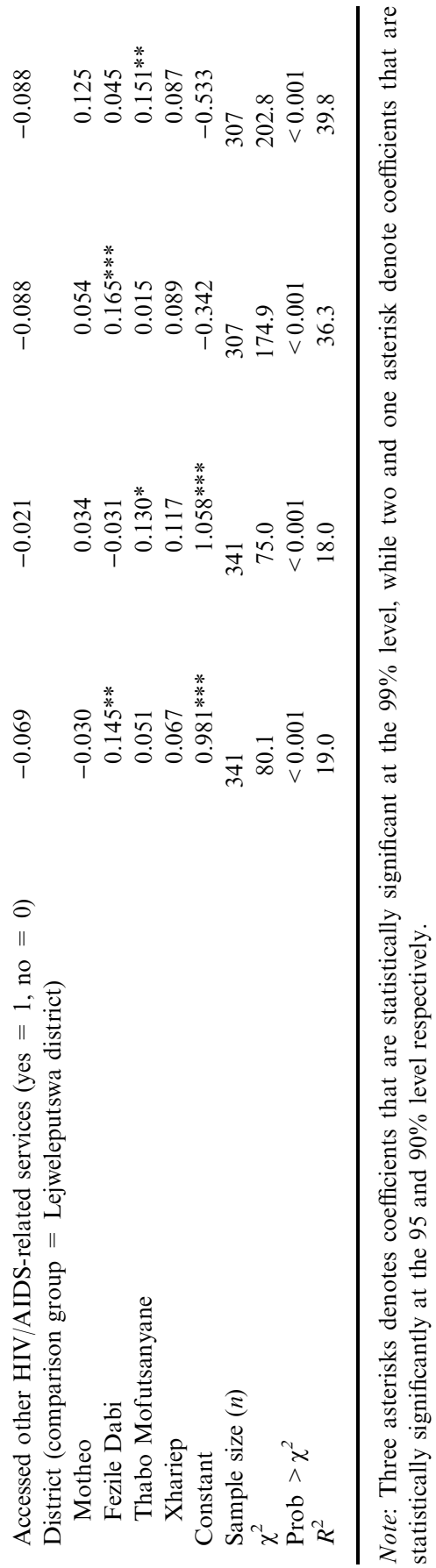


association of quality of life with the interaction between access to treatment and HRQOL, with perceived stigmatisation, and with perceived quality of health care services disappear when adjusting for satisfaction on main life domains.

Patients with a treatment buddy are significantly happier with life, while those who visited a traditional health care practitioner since joining the ART programme are significantly less happy with life. This remains the case, even when adjusting for differences in satisfaction on main life domains. QOL also differ significantly by district. Respondents from the Fezile Dabi and Thabo Mofutsanyane districts report significantly different levels of life satisfaction compared with respondents from Lejweleputswa district, even when adjusting for differences in satisfaction on main life domains.

In the full model, respondents' satisfaction on six main life domains is significantly and positively associated with overall quality of life. Life satisfaction and happiness increases as satisfaction with personal life and family's health increases. Life satisfaction also rises as satisfaction with housing increases, while happiness increases as satisfaction with family life, food and education rises.

When adjusting for these differences in satisfaction on main life domains, three other factors exhibit a statistically significant association with quality of life. Patients with access to a physical caregiver are significantly more satisfied and happier with life in general, while patients who are members of HIV/AIDS support groups are significantly happier with life. In addition, the length of time for which patients have known their HIV-positive status is weakly correlated with life satisfaction. Study participants who have been aware of their HIV-positive status for more than 2 years, reported lower life satisfaction compared with patients who have known their HIV status for less than twelve months.

\subsection{Factors Associated with Improvements in the Physical Health and Emotional Well-Being of Patients Ready to Commence ART}

In terms of the socio-demographic and socio-economic characteristics of study participants, only age is statistically significantly associated with the probability of reporting improvements in physical health. As expected, the probability of reporting improvements in physical health declines with age. As was the case above, the probability of improvements in physical health and emotional well-being differ significantly across health districts (see Table VII).

Patients whose first HIV-positive test was prompted by illness, rather than exposure to risk of infection and/or the routine/voluntary uptake of testing, 


\section{TABLE VII}

Bivariate probit model of self-reported improvements in physical health and emotional well-being of patients, total sample

\begin{tabular}{|c|c|c|}
\hline Independent variable & $\begin{array}{l}\text { Physical } \\
\text { health } \\
\text { improved }\end{array}$ & $\begin{array}{l}\text { Emotional } \\
\text { well-being } \\
\text { improved }\end{array}$ \\
\hline Age & $-0.015^{*}$ & -0.001 \\
\hline Gender $($ male $=1$, female $=0)$ & 0.163 & 0.148 \\
\hline \multicolumn{3}{|l|}{ Marital status (comparison group $=$ single) } \\
\hline Married and living together & -0.016 & 0.158 \\
\hline Married but not living together & -0.259 & -0.256 \\
\hline \multicolumn{3}{|l|}{ Highest level of education (comparison group $=$ none) } \\
\hline Primary education & 0.171 & -0.388 \\
\hline Some secondary education & 0.190 & -0.361 \\
\hline Grade 12 or tertiary education & -0.035 & -0.451 \\
\hline \multicolumn{3}{|l|}{ Employment status (comparison group $=$ unemployed) } \\
\hline Informally employed & -0.135 & 0.181 \\
\hline Formally employed & 0.055 & 0.555 \\
\hline \multicolumn{3}{|l|}{ Dwelling type (comparison group $=$ formal dwelling) } \\
\hline Informal dwelling & 0.138 & 0.184 \\
\hline Traditional dwelling & -0.510 & 0.126 \\
\hline \multicolumn{3}{|l|}{$\begin{array}{l}\text { Knowledge of HIV }+ \text { status } \\
\text { (comparison group }=<12 \text { months) }\end{array}$} \\
\hline $12-24$ months & -0.185 & 0.264 \\
\hline $25+$ months & -0.118 & 0.114 \\
\hline Illness prompted HIV test (yes $=1$, no $=0$ ) & $0.346^{*}$ & 0.263 \\
\hline Receiving antiretroviral treatment $($ yes $=1$, no $=0$ ) & $0.526^{* *}$ & -0.108 \\
\hline Commenced ART $*$ Health-related quality of life (EQ-5D) & $1.009 * * *$ & $1.228 * * *$ \\
\hline Hospitalised since joining ART programme $($ yes $=1$, no $=0$ ) & -0.105 & $0.849^{* *}$ \\
\hline Stigmatisation scale & 0.019 & 0.002 \\
\hline Disclosed prior to DRT $*$ Stigmatisation scale & -0.084 & -0.037 \\
\hline Quality of health care services & 0.153 & 0.114 \\
\hline Receives food supplements (yes $=1$, no $=0$ ) & $0.571^{* * *}$ & $0.441^{* *}$ \\
\hline Has a treatment buddy $($ yes $=1$, no $=0$ ) & $0.507 * *$ & $0.576^{* *}$ \\
\hline Visited by a community health care worker $($ yes $=1$, no $=0$ ) & $3.983 * * *$ & $1.081^{* *}$ \\
\hline Member of HIV/AIDS support group (yes $=1$, no $=0$ ) & 0.086 & 0.476 \\
\hline Has an emotional caregiver $($ yes $=1$, no $=0)$ & -0.256 & -0.025 \\
\hline Has a physical caregiver $($ yes $=1$, no $=0$ ) & 0.106 & $0.364 *$ \\
\hline Visited a traditional health care practitioner $($ yes $=1$, no $=0$ ) & -0.057 & -0.290 \\
\hline Accessed other HIV/AIDS-related services (yes $=1$, no $=0$ ) & 0.198 & $6.175^{* * *}$ \\
\hline \multicolumn{3}{|l|}{ District $($ comparison group $=$ Lejweleputswa district) } \\
\hline Motheo & $0.627^{*}$ & $0.839^{* * *}$ \\
\hline Fezile Dabi & -0.356 & 0.027 \\
\hline Thabo Mofutsanyane & $-0.582 * *$ & $-0.658 * *$ \\
\hline Xhariep & -0.079 & -0.197 \\
\hline Sample size $(n)$ & & 342 \\
\hline Wald $\chi^{2}$ & & 7308.6 \\
\hline
\end{tabular}


TABLE VII

Continued

\begin{tabular}{llc}
\hline Independent variable & $\begin{array}{l}\text { Physical } \\
\text { health } \\
\text { improved }\end{array}$ & $\begin{array}{l}\text { Emotional } \\
\text { well-being } \\
\text { improved }\end{array}$ \\
\hline Prob $>\chi^{2}$ & & $<0.001$ \\
Wald $\chi^{2}$ test of $\rho=0$ & 42.1 \\
Prob $>\chi^{2}$ & $<0.001$ \\
\hline
\end{tabular}

Note: Three asterisks denotes coefficients that are statistically significant at the $99 \%$ level, while two and one asterisk denote coefficients that are statistically significantly at the 95 and $90 \%$ level respectively.

are significantly more likely to have reported improvements in physical health. This is understandable insofar as these patients were probably more ill when coming forward for treatment, are more likely to have therefore been put on treatment, and thus are more likely to have benefited from accessing treatment. Access to ARVs also significantly increases the probability of patients reporting an improvement in their physical health since joining the ART programme. As with the first set of QOL measures, patients who have commenced taking ARVs and who experienced improvements in HRQOL are also significantly more likely to have reported an improvement in their physical health and emotional well-being since joining the ART programme.

Access to support and care again are important in explaining differences in the probability of improvements in physical health and emotional wellbeing. Patients who receive food supplements, who have a treatment buddy and who have been visited by a community health care worker are significantly more likely to have reported improvements in not only physical health, but also emotional well-being. In turn, those patients who accessed HIV/AIDS-related services provided by other organisations also are significantly more likely to have reported improvements in their emotional well-being, as are patients with access to a physical caregiver.

\subsection{Factors Associated with Differences in the Life Satisfaction and Happiness of Patients Receiving ARVS}

As was the case in the aggregate model, married respondents not cohabiting with their partners or spouses report significantly lower levels of life satisfaction and happiness compared with single respondents. This association 
THE HEART IN HAART

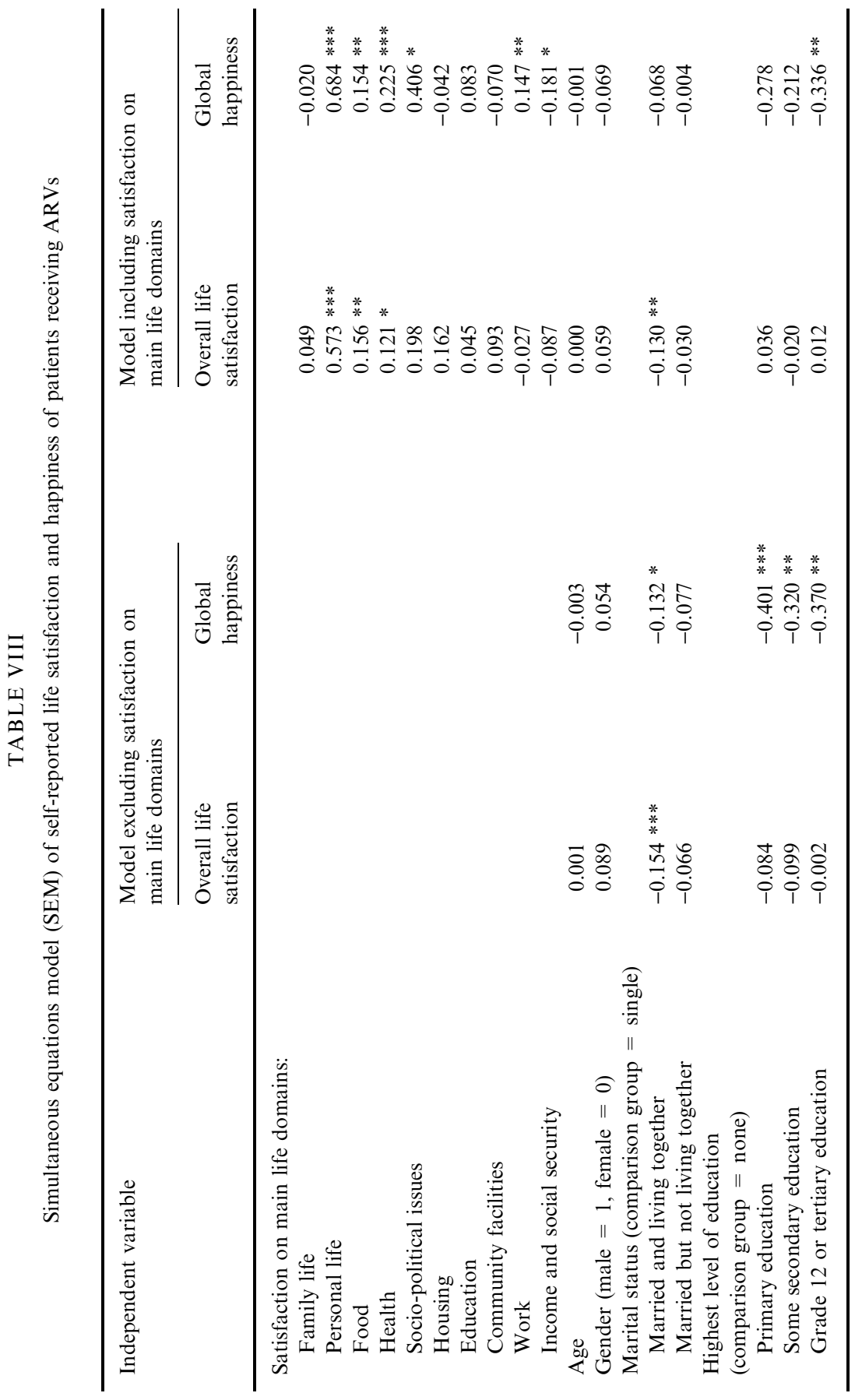




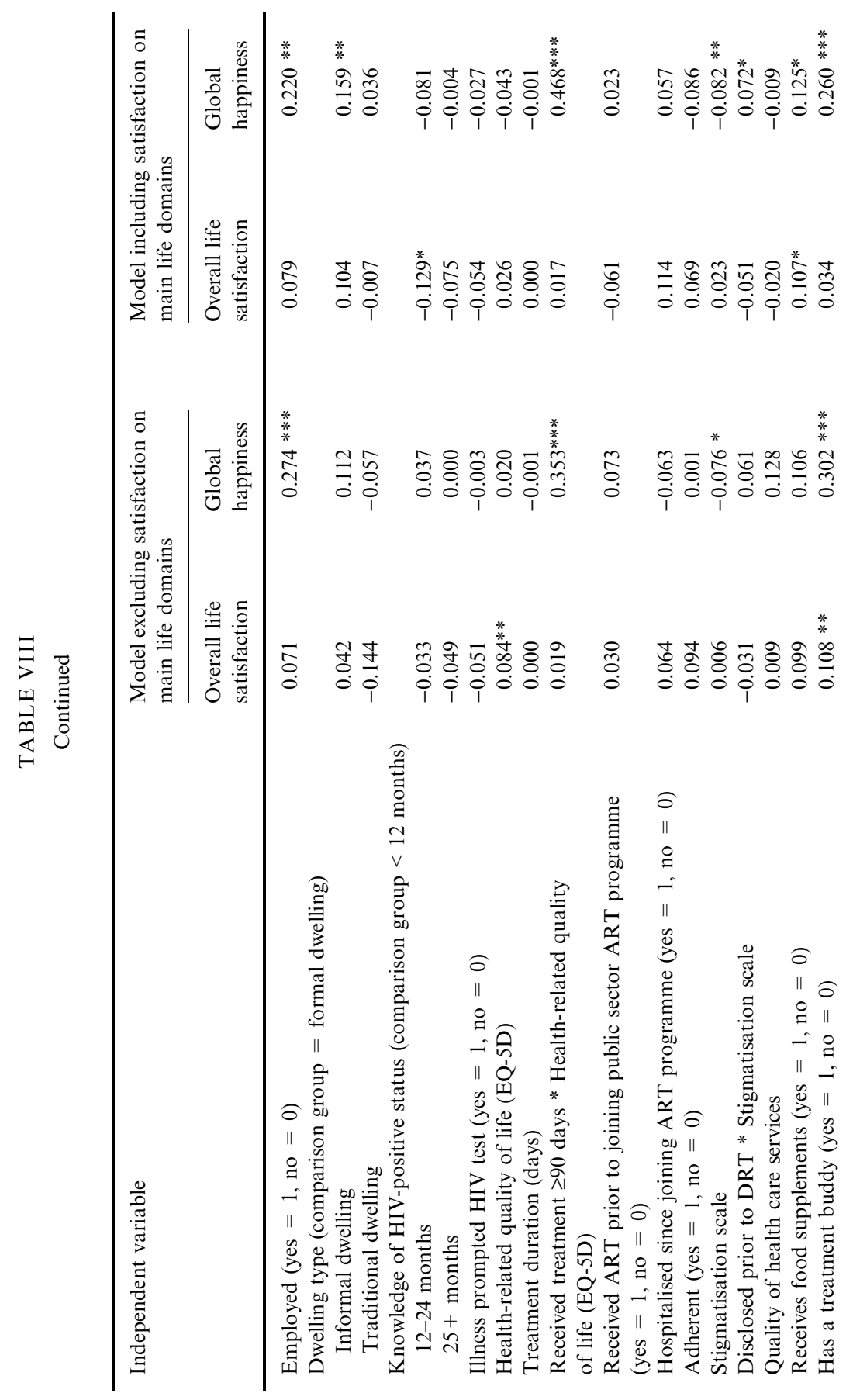




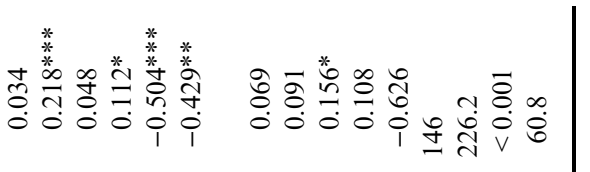

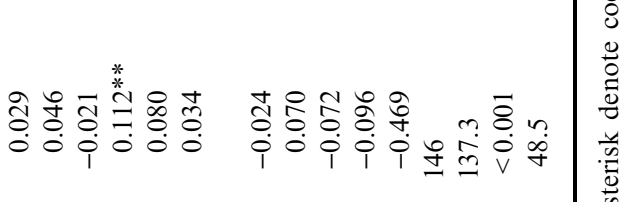

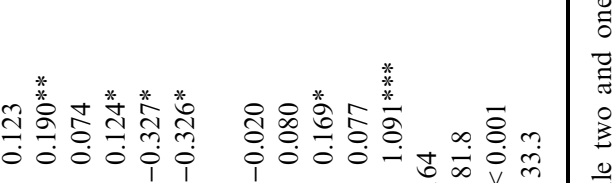

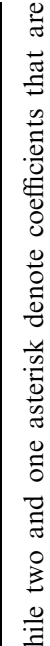

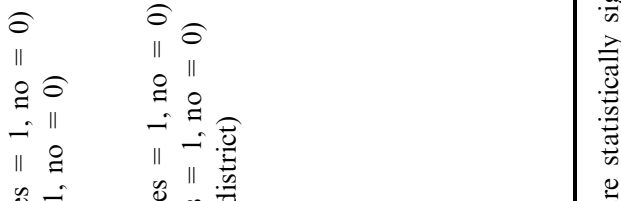

$\ddot{0}=0 \stackrel{0}{0}$

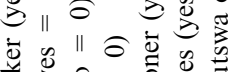

웜

३ิ)

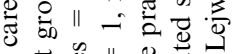

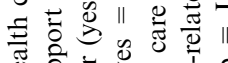

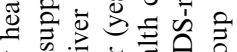

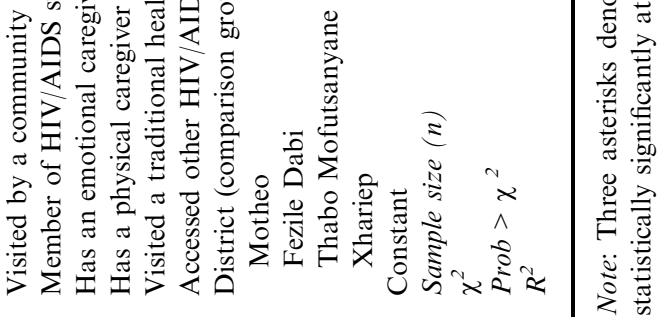


between marital status and overall life satisfaction persists, even when adjusting for differences in satisfaction on main life domains. There is also a strong education gradient in reports of happiness, with patients with formal education reporting significantly higher levels of happiness compared with the uneducated, even when adjusting for differences in satisfaction on main life domains. Employed persons are significantly happier compared with unemployed person, even when adjusting for differences in satisfaction on main life domains. Patients in Thabo Mofutsanyane district taking ARVs are significantly happier compared with patients from the Lejweleputswa district (see Table VIII).

Among patients who have commenced taking ARVs, life satisfaction increases significantly with HRQOL. Where patients have been taking ARVs for more than three months, further increases in HRQOL are associated positively and significantly with happiness. Patients who perceive less stigmatisation are significantly happier with life in general. Patients with access to a treatment buddy also report significantly higher levels of life satisfaction and happiness compared with those without a treatment buddy, as do patients with access to a physical caregiver. Patients who are members of HIV/AIDS support groups are significantly happier with life. Yet, patients who accessed a traditional health care practitioner or who accessed HIV/AIDS-related services provided by other organisations report significantly lower levels of happiness. Except for the association between HRQOL and life satisfaction and between access to a treatment buddy and life satisfaction, these associations between QOL and various treatment experiences remain statistically significant, even when adjusting for differences in satisfaction on main life domains.

In the full model, respondents' satisfaction on six main life domains is significantly associated with overall quality of life. Life satisfaction and happiness increases as satisfaction with personal life, food and family's health increases. Satisfaction with socio-political issues and work is also positively and significantly associated with global happiness. Yet, satisfaction with income and social security is negatively and significantly associated with global happiness. The latter result suggests that patients taking ARVs for the most part are happy with life in general, but not with income and social security issues (refer Figures 1 and 2).

When adjusting for differences in satisfaction on main life domains, however, three other factors exhibit a statistically significant association with quality of life. Compared with patients who live in formal dwellings, patients living in informal dwellings are significantly happier. ${ }^{16}$ Patients who have been aware of their HIV-positive status for 12-24 months are signifi- 
cantly less satisfied with life compared to patients who have known their HIV status for a shorter period of time. In addition, patients on ART receiving food supplements are significantly more satisfied and happier with life in general compared with those not receiving food supplements.

\subsection{Factors Associated with Improvements in the Physical Health and Emotional Well-Being of Patients Receiving ARVS}

Unlike in the case of patients selected for ART, patients who have commenced ART differ significantly in respect of a number of sociodemographic and socio-economic characteristics. Again, the probability of improvements in physical health declines significantly with age. Yet, the probability of improvements in emotional well-being also declines significantly with age. In addition, male patients are significantly more likely to have reported improvements in emotional well-being when compared with female patients. Married respondents not living with their partners or spouses are less likely to have reported improvements in their physical health compared with single respondents. Respondents who completed their secondary education or have some tertiary education are significantly more likely to have reported improvements in physical health compared with patients with no formal education (see Table IX).

Dwelling type is also significantly associated with improvements in subjective well-being. On the one hand, patients living in traditional dwellings are significantly less likely to have reported improvements in physical health compared with patients living in formal dwellings. On the other hand patients living in informal dwellings are significantly more likely to have reported improvements in emotional well-being when compared with patients residing in formal dwellings.

Higher levels of HRQOL translate into a significantly higher probability of having reported improvements in not only physical, but also emotional well-being. Where patients have been taking ARVs for more than three months, however, further increases in HRQOL are associated with a significantly smaller probability of reporting improvements in physical health and emotional well-being. As expected, patients who have been hospitalised since joining the ART programme are significantly less likely to have reported an improvement in physical health. Interestingly, moreover, patients who have known their HIV + status for 2 years or longer are significantly more likely to have reported an improvement in emotional wellbeing compared with patients who have been aware of their HIV-positive status for less than 1 year. 


\section{TABLE IX}

Bivariate probit model of self-reported improvements in physical health and emotional wellbeing of patients receiving ARVs

\begin{tabular}{|c|c|c|}
\hline Independent variable & $\begin{array}{l}\text { Physical } \\
\text { health } \\
\text { improved }\end{array}$ & $\begin{array}{l}\text { Emotional } \\
\text { well-being } \\
\text { improved }\end{array}$ \\
\hline Age & $-0.025 * *$ & $-0.023 * *$ \\
\hline Gender $($ male $=1$, female $=0)$ & 0.285 & $0.771^{* *}$ \\
\hline \multicolumn{3}{|l|}{ Marital status (comparison group $=$ single) } \\
\hline Married and living together & 0.301 & -0.277 \\
\hline Married but not living together & $-0.665^{* *}$ & -0.056 \\
\hline \multicolumn{3}{|l|}{ Highest level of education (comparison group $=$ none) } \\
\hline Primary education & 0.549 & -0.605 \\
\hline Some secondary education & 0.534 & -0.479 \\
\hline Grade 12 or tertiary education & $0.934 *$ & -0.160 \\
\hline \multicolumn{3}{|l|}{ Dwelling type (comparison group = formal dwelling) } \\
\hline Informal dwelling & 0.271 & $0.754^{*}$ \\
\hline Traditional dwelling & $-0.994 * *$ & -0.274 \\
\hline \multicolumn{3}{|l|}{$\begin{array}{l}\text { Knowledge of HIV-positive status } \\
\text { (comparison group }=<12 \text { months) }\end{array}$} \\
\hline $13-24$ months & 0.043 & 0.287 \\
\hline $25+$ months & 0.177 & $1.025 * * *$ \\
\hline Illness prompted HIV test $($ yes $=1$, no $=0)$ & 0.308 & 0.352 \\
\hline Health-related quality of life (EQ-5D) & $1.819 * * *$ & $2.850 * * *$ \\
\hline Treatment duration (days) & 0.003 & -0.004 \\
\hline $\begin{array}{l}\text { Received treatment }>=90 \text { days } * \text { Health-related } \\
\text { quality of life }(E Q-5 D)\end{array}$ & $-1.276^{*}$ & $-2.114 * * *$ \\
\hline $\begin{array}{l}\text { Received ART prior to joining public sector ART programme } \\
(\text { yes }=1 \text {, no }=0)\end{array}$ & 0.365 & -0.483 \\
\hline Hospitalised since joining ART programme $($ yes $=1$, no $=0$ ) & $-1.028 * *$ & 0.431 \\
\hline Stigmatisation scale & 0.134 & -0.133 \\
\hline Disclosed prior to DRT $*$ Stigmatisation scale & -0.224 & 0.019 \\
\hline Quality of health care services & -0.406 & -0.230 \\
\hline Receives food supplements (yes $=1$, no $=0$ ) & $0.834^{* *}$ & $1.049 * * *$ \\
\hline Has a treatment buddy $($ yes $=1$, no $=0$ ) & $0.696 * * *$ & $0.656^{* *}$ \\
\hline Visited by a community health care worker $($ yes $=1$, no $=0$ ) & 7.218 & $1.167 * *$ \\
\hline Member of HIV/AIDS support group (yes $=1$, no $=0$ ) & -0.164 & 0.299 \\
\hline Has an emotional caregiver $($ yes $=1$, no $=0$ ) & -0.265 & -0.183 \\
\hline Has a physical caregiver $($ yes $=1$, no $=0)$ & $0.501 *$ & $0.733 * * *$ \\
\hline Visited a traditional health care practitioner (yes $=1$, no $=0$ ) & -0.509 & -0.724 \\
\hline Sample size ( $n$ ) & & 205 \\
\hline Wald $\chi^{2}$ & & 376.8 \\
\hline Prob $>\chi^{2}$ & & $<0.001$ \\
\hline
\end{tabular}


TABLE IX

Continued

\begin{tabular}{llc}
\hline Independent variable & $\begin{array}{l}\text { Physical } \\
\text { health } \\
\text { improved }\end{array}$ & $\begin{array}{c}\text { Emotional } \\
\text { well-being } \\
\text { improved }\end{array}$ \\
\hline $\begin{array}{l}\text { Wald } \chi^{2} \text { test of } \rho=0 \\
\text { Prob }>\chi^{2}\end{array}$ & 32.0 \\
\hline
\end{tabular}

Note: Employment status, adherence, access to HIV/AIDS-related services provided by other organisations, and district were dropped from the model as these variables did not vary significantly across the independent variables to allow the model to be estimated. Three asterisks denotes coefficients that are statistically significant at the $99 \%$ level, while two and one asterisk denote coefficients that are statistically significantly at the 95 and $90 \%$ level respectively.

As was the case with patients in general, patients on ARVs that have treatment buddies are significantly more likely to have reported improvements in not only their physical health, but also their emotional well-being, as are patients who receive food supplements and who have a physical caregiver. In addition, patients visited by a community health care worker are significantly more likely to also have reported an improvement in their emotional well-being.

\section{DISCUSSION}

Although reported levels of happiness are in line with levels of happiness reported for the general South African population (Møller and Dickow, 2002), study participants are very satisfied with life, even more so than South Africans in general (Møller and Dickow, 2002). This surprising result may be attributed to three possible explanations, which together may explain this finding. Firstly, there is the role of the reference group (Van Praag and Ferrer-I-Carbonell, 2004). Study participants may be relatively satisfied with their lives if they are comparing themselves with those persons with HIV/AIDS who do not have access to ART.

In the second instance, there is the possibility of adaptation (BiswasDiener and Diener, 2001; Echteld et al., 2005; Evans and Huxley, 2005) or what Hajiran (2006, p. 37) describes as the law of declining "marginal utility of happiness or marginal disutility of sadness". Patients may have adapted to their situation and therefore may report significantly higher levels of life satisfaction compared to when they first learned that they are HIV-positive. In fact, study participants have known their HIV-positive status for a relatively long period of time (mean $=22$ months, median $=10$ months). 
Thus, they may very well have adapted to living with their illness (Van Praag and Ferrer-I-Carbonell, 2004). In fact, evidence from the literature also suggests that people living in adverse conditions can be relatively satisfied and happy with their lives (Biswas-Diener and Diener, 2001).

In the third instance, the result may simply reflect the fact that many of these patients are not as severely ill. In December 2004 for example median pre-treatment CD4 counts for ART patients in the Free State province exceeded $100 \times 10^{6}$ cells $/ 1$, this compared to a median of $43 \times 10^{6}$ cells $/ 1$ only for patients enrolled in a treatment initiative in Khayelitsha, Cape Town. Furthermore, relatively few of these patients were classified as being in WHO stage 4 (Coetzee et al., 2004; Free State Department of Health, 2005).

According to the results from the bivariate analysis, levels of overall life satisfaction and happiness do not exhibit clear-cut and consistent differences by treatment status. Patients taking ARVs are however significantly more likely to have reported improvements in physical and emotional well-being compared with patients awaiting treatment. Both sets of quality of life measures are significantly associated with treatment duration. The results suggest that there may be a sustained subjective 'health effect' associated with time on ART. There is evidence that the mere fact of having started treatment initially may be associated with greater happiness and improved emotional well-being. This psychological or psychosocial 'treatment effect' however dissipates as treatment duration increases, possibly due to the fact that study participants as time increased may have adapted to the novelty of having access to treatment. In the case of overall life satisfaction, however, significantly higher levels of quality of life are only reported in patients who have been taking ARVS for 3 months or longer, or in other words, in those who are more likely to have already benefited from the documented medical or clinical benefits of ART. Further follow-up of study participants will enable us to determine whether overall life satisfaction declines as treatment duration further increase, as did the probability of reporting improvements in emotional well-being.

As in the case of the bivariate analysis, access to treatment is not independently associated with quality of life. The evidence shows however that quality of life is positively associated with health status or HRQOL, as well as with treatment duration, which is important in determining when the medical or clinical benefits of ART are actually realised. Yet, the evidence again suggests that improvements in subjective-well-being, for the same reasons elaborated on above, may dissipate and even decline as treatment duration continues to increase. 
Patients selected for ART who first tested HIV-positive following an illness episode are significantly more likely to have reported improvements in their physical health since joining the ART programme when compared to patients who tested for other reasons. As these patients have also known their HIV status for a significantly shorter period of time and as they may be relatively more ill compared to those who tested for other reasons, it is not altogether surprising. For the same reasons, the fact that these patients are significantly less happy is also not surprising. Once on ARVs, patients who have known their HIV-positive status for longer are shown to be significantly more likely to have reported improvements in emotional wellbeing compared with patients who have only learnt of their HIV status in the more recent past. This hints at the important role of knowledge of one's HIV status in coping emotionally with living with HIV and AIDS. Surprisingly, however, the results also suggest that patients who have known their HIV-positive status for longer are significantly less satisfied with life compared to those who have known their HIV-positive status for a shorter duration of time, albeit that these coefficients are only significant at the $10 \%$ level. It is not clear what the explanation is for this result and further research is required to untangle the relatively complex links between the timing of HIV-testing when first tested HIV-positive and the various aspects of treatment experiences.

Importantly, quality of life is also associated negatively with perceived stigmatisation, in the case of those selected for ART as well as in the case of those receiving ART. Thus, efforts are required to lower the stigmatisation of and discrimination against PLWA to change the "perception of HIV/ AIDS from a personal to a public health problem" (Alubo et al., 2002, p. 117). Klein et al. (2002) distinguish between three main types of interventions or strategies to address HIV/AIDS-related stigma and discrimination: statutory or regulatory interventions, the development of policies on HIV/AIDS, and the provision of a variety of HIV/AIDS services and programmes that can curb stigma. Media campaigns and the distribution of information however seem to not have succeeded in lowering stigma (Cobb and De Chabert, 2002). Yet, this may be the result of using inappropriate channels to enforce these messages and to share such information with target populations, with social marketing strategies for example being shown to represent a very effective means of communication (Busza, 2001). Laws and policies in turn will only succeed in reducing stigma if implemented and enforced. The development of responses to stigma further requires knowledge of the extent to which HIV stigma may in fact be layered or in other words entails the "co-occurrence of multiple stigmatising 
attributes" (Reidpath and Chan, 2005, p. 425). If so, then different interventions may be required to address different aspects of stigmatisation (Chen et al., 2005).

Quality of life is positively associated with the perceived quality of health care services. Murri et al. (2003), who like Preau et al. (2004) found satisfaction with information to be significantly associated with HRQOL, highlight the fact that satisfaction with health care services is most amenable to intervention when those aspects of health care services patients are least satisfied with have been identified. In this particular dataset, the items in the health care quality scale with the lowest scores deals with waiting times during consultations at treatment and assessment sites as well as complaint procedures at assessment sites.

The role of food supplements, a treatment buddy, as well as access to not only a physical caregiver, but also a community health care worker, an HIV/ AIDS support group, and even HIV/AIDS-related services provided by other organisations are key in enhancing the quality of life of patients enrolled in the ART programme and those who have commenced ART. Gielen et al. (2001) and Stewart et al. (2005) similarly found access to social support to be important in enhancing the QOL of PLWA, while Crook et al. (2005) and Makoae et al. (2005) highlight the importance of communitybased support services. Yet, access to such support mechanisms may on the one hand be dependent on disclosure (D'Angelo et al., 2001; Klitzman et al., 2004). In the dataset, for example, access to a physical caregiver is significantly associated with disclosure, both for patients selected for ART as well as for those who have started taking ARVs $(p<0.10)$. On the other hand, accessing care and support (including ART) may be a stigmatising experience in itself (Alubo et al., 2002; Kalichman and Simbayi, 2004; Paxton et al., 2005), or may represent an effort to deal with such stigma. For example, patients who have accessed food supplements, who were visited by a community health care worker, or who accessed HIV/AIDS-related services provided by other organisations report significantly higher levels of perceived stigma $(p<0.10)$. Patients with access to an emotional caregiver in turn report significantly lower levels of perceived stigma $(p<0.01)$. Given, moreover, that disclosure and stigma are intertwined (Busza, 2001), further work is required to untangle these complex links between disclosure, stigma and access to support and care.

Causality between dependent and independent variables cannot be established using cross-sectional data such as these. Thus, the reported negative associations between QOL and access to other types of support and care, notably traditional health care and HIV/AIDS-related services provided by 
other organisations, may simply suggest that patients with a lower quality of life have accessed such services, perhaps in an attempt to help remedy those difficulties causing them to be dissatisfied or unhappy with their lives, including the fact that they may not have had access to ART or other types of care and support. This makes sense insofar as the use of traditional health care practitioners in fact is statistically significantly higher among those awaiting treatment $(9.7 \%)$ than those receiving ARVs $(4.5 \%)(p<0.05)$. Sugimoto et al. (2005) suggest moreover that traditional medicine may be particularly important in enhancing the QOL of PLWA who cannot access ART.

In numerous instances, the significant association of some independent variables with life satisfaction or happiness, most notably employment status, housing characteristics, health status (or HRQOL), stigmatisation and quality of health care services, disappear when adjusting in the analysis for differences in satisfaction with main life domains. This most probably is the result of the association of these factors with the two QOL measures being mediated by their impact on satisfaction with various specific or main life domains. An analysis of the correlation between these variables and satisfaction with specific and main life domains for example reveal the following: dwelling type is significantly associated with satisfaction with housing and community facilities $(p<0.01)$. More specifically, satisfaction with each of the individual components of the housing domain (refer Figure 2) and with satisfaction with public services is significantly associated with dwelling type $(p<0.01)$. HRQOL in turn is positively and significantly correlated with satisfaction with a number of main life domains, including family life, personal life, family health and socio-political issues $(p<0.01)$. Perceived stigma correlates negatively with satisfaction with family life, family health and housing $(p<0.01)$. Quality of health care services is positively and significantly associated with satisfaction with as many as five main life domains: personal life, food, education, socio-political issues, and community facilities $(p<0.01)$. Similar results have been documented in quality of life studies, especially in regards to health status (Michalos, 2004). Thus, differences in living standards, health status, stigmatisation and quality of health care services in some instances do not directly impact on QOL of life, but rather affect overall life satisfaction or happiness indirectly. Yet, these factors in some cases are significantly associated with quality of life, even when adjusting for differences in satisfaction with main life domains. Here, the evidence suggests that living standards, health status (or HRQOL) and stigmatisation are independently associated with quality of life. 


\section{CONCLUSIONS}

To summarise, it is not access to treatment per se that enhances the quality of life of those who have come forward for ART. Rather, it is the health benefits associated with treatment, represented here by improvements in HRQOL that are realised as treatment duration increases, levels of stigmatisation, quality health care services, and the ability of persons to access certain types of support and care, both from within and outside the health care sector, that explain differences in the quality of life of patients enrolled in the public sector ART programme. In other words, it is the wider context and environment within which treatment is provided to patients that ultimately determines differences in improvements in and levels of the quality of life of ART patients. The challenge, therefore, is to ensure those living with HIV and AIDS of equitable access to ARVs, to break down stigma towards those living with HIV and AIDS, and to deliver antiretroviral treatment via a quality, multifaceted and integrated health care programme.

\section{NOTES}

1 Antiretroviral treatment in this paper refers to highly active triple drug therapy (HAART), although we elsewhere in the text employ the more commonly used 'antiretroviral treatment', or in short 'ART'. The argument here that these studies 'concur' as to the economic feasibility of ART derives from the fact that almost all published evaluations conclude that treatment presents a cost-effective intervention. Admittedly, such statements need to be interpreted with care, as argued so convincingly by Marseilles et al. (2002) and Creese et al. (2002), given that the results of economic evaluations due to a variety of reasons are not transferable across settings, not between developed and developing countries, nor between developing countries, nor even necessarily within the same country (Jack, 1999; Jefferson et al., 2000; Drummond and Pang, 2001).

2 These benefits must be covered by all benefit options offered by private medical schemes, while the use of monetary limits, levies and co-payments are prohibited for coverage of these minimum benefits (Forman et al., 2004). In respect of other HIV/AIDS-related care and treatment options, the list of prescribed minimum benefits also includes treatment of HIV-associated disease, sexually transmitted diseases, as well as comfort care and pain relief when death is imminent (Pearmain, 2000). 
Provision of care for prescribed minimum benefits is guided by specified clinical protocols and criteria. In addition, funds are prohibited to employ monetary limits, levies and co-payments in respect of coverage of prescribed minimum benefits (Forman et al., 2004)

3 Whereas the studies that have documented the impact of ART on quality of life employ mainly generic or disease-specific measures of quality of life to assess health outcomes, quality of life studies assess satisfaction or happiness with life in general (see Michalos, 2004).

4 The programme did not commence simultaneously in all five health districts. The sampling frame excludes patients eligible for ART, but who were not certified as ready to commence with treatment, in many cases due to them having to first complete their tuberculosis treatment. Thus, the results cannot be generalised to all patients eligible for ART, but rather to public sector patients ready to commence ART following clinical assessment.

5 Admittedly, the ideal would be to compare the quality of life of these patients, who have already accessed the public health care system in search for treatment, with those persons eligible for treatment who have not presented at public health facilities, but also with infected individuals not yet eligible for treatment. Given budgetary and logistical constraints, however, this study design was adopted as it also allows periodic assessments of various aspects of patients' experiences with and perceptions of the public sector ART programme in the Free State province.

6 During the sampling procedure, a total of 194 treatment and 173 nontreatment cases were sampled for inclusion in the study $(n=267)$. A total of four additional interviews were conducted during the survey compared to the number of sampled respondents. These observations are included in the analysis, given the random nature of the sample. Given the lapse of time moreover between when the sample was drawn and when interviews were conducted (mostly due to the time necessary to make contact with sampled respondents and to set up interviews), a number of patients sampled as non-treatment cases had actually started taking ARVs by the time the interview was conducted. This resulted in a different distribution of observations between the so-called treatment and non-treatment groups in the actual dataset, or to be more specific, an overrepresentation of treatment cases compared to non-treatment cases.

7 The conventional approach in quality of life studies is followed in calculating mean scores on life satisfaction and happiness scales, with 'don't know' responses assigned to the undecided category of 'neither satisfied 
nor dissatisfied' or 'neither happy nor unhappy', whereas missing values are excluded from the analysis. Mean scores and satisfaction levels for the ten main life domains represent the averages of the scores and satisfaction levels for the respective items in each main life domain.

8 As the references are too numerous to provide here, interested readers can contact the first author to obtain these bibliography details.

9 The EuroQol (EQ) questionnaire is a standardised generic Health Related Quality of Life instrument for comparing studies developed by the international research network EuroQol Group in 1987. The EuroQol instrument has been tested and validated in a variety of settings (EssinkBot et al., 1997; Delate and Coons, 2001; Wu et al., 2002), including studies of HIV-positive respondents in developed and developing countries (Kind et al., 1988; Hurst et al., 1997; Hughes et al. 2004) and studies in South Africa (Jelsma et al., 2004; Jelsma and Ferguson, 2004), including a study of our own study population (Louwagie et al., 2006). The EQ-5D index assesses health status in five domains: mobility, selfcare, usual activities, pain/discomfort, and anxiety/depression. Each domain is answerable by 3 statements indicating no problem (1), some/ moderate problems (2) or extreme problems (3). Responses to these five items were combined to derive a weighted single index value describing health status using the York tariffs, which were generated from a survey of over 3000 adults in the United Kingdom in the early 1990s (Bowling, 2005). The resulting index can be regarded as a societal value of the respondent's health status (Krabbe and Weijnen, 2003). The index ranges from -0.594 to 1 , with negative values referring to health states valued as worse than death.

10 In terms of quality of care at drug-readiness training (DRT), patients were asked how satisfied they are with the clarity of information provided, opportunities to ask questions, thorough discussion of information, information provided about HIV/AIDS and about ARV medication, and the language used during the training. Questions of the quality of care at assessment and at treatment sites focused on patients' satisfaction with medical care, complaint procedures, cleanliness, privacy during examinations, confidentiality of medical records, respect shown by nurses and doctors, information provided about HIV/AIDS and about ARV medication by nurses and doctors, opportunities to ask health care workers questions, the language used during consultations, the hours that the facility is open, and waiting times before consultations. 
11 Government finances the stipends paid to community health care workers (currently R500/month). The actual service however is provided by contracted non-governmental organisations (NGOs) and communitybased organisations (CBOs). These organisations train and oversee the work of community health care workers, who provide a variety of public health services, including DOTS support for tuberculosis patients, homebased care, counselling and ARV patient support.

12 The so-called treatment buddy (this is the terminology employed in the policy and treatment guidelines) currently is the main source of informal support: during drug readiness training patients are asked to find a treatment buddy and to bring the person along to subsequent drug readiness training sessions. The main role of treatment buddies, who are unpaid volunteers, is to support ART patients in taking their medication and to thus ensure adherence. Treatment buddies also offer emotional support to patients. Services provided by other organisations for the most part include counselling services provided by NGOs, CBOs and other organisations, as well as physical care.

13 Similarly, dummy variables can be included in the econometric models for each of the specific health care facilities (assessment or treatment sites), which would capture differences in QOL explained by unobserved differences between health care facilities. However, this would constrain the degrees of freedom considerably. Furthermore, the sample, although stratified by facility (refer sampling design), do not include adequate numbers to allow comparisons between facilities. Comparisons can only be made at the district level with any degree of certainty. Hence, these facilities dummies were not included in the regression models.

14 The framework presented here represents the author's interpretation of how Veenhoven's (2000) ideas can be employed to ground the approach to quality of life studies employed here within an existing theoretical framework. For example, self-reported perceptions of stigma and discrimination and the satisfaction of people with their own lives in respect of their perceptions as to how they are valued by others in the community (in this case, community members, friends and other race groups) are situated here in the bottom left quadrant. As Veenhoven (2000) rightly points out, such evaluation of the utility of people's lives theoretically should be performed not by these person's themselves, but by others in the community. However, such data are not available here and in fact normally are not collected. Thus, these measures are employed here as proxy only of these particular aspects of quality of life. 
15 The overall life satisfaction and global happiness scales are significantly correlated $(r=0.458, p<0.001)$. Improvements in physical and emotional well-being are also significantly associated $(p<0.001)$. A total of $80.3 \%$ of study participants reporting improved physical health also reported improvements in emotional well-being. In turn, a total of $89.6 \%$ of respondents that reported improved emotional well-being also reported improved physical health.

16 In South African QOL studies people living in informal settlements are generally shown to be less happy than people living in formal dwellings. Here, however, patients on ARVs living in informal settlements reported significantly higher levels of global happiness and were also significantly more likely to have reported improvements in emotional well-being compared with patients living in formal dwellings (refer Tables VIII and IX). Among patients receiving ARVs, those living in informal dwellings did report significantly higher levels of HRQOL than patients living in formal and traditional dwellings ( $p<0.05$ ). Yet, it is unclear as to why this group of study participants reported higher happiness scores and greater improvements in emotional well-being when adjusting for these differences in HRQOL and a range of other factors. A possible explanation is the 'reference group' effect, which may be larger in the relatively deprived group (those living in informal settlements) than in the less deprived group (those residing in formal dwellings).

\section{ACKNOWLEDGEMENTS}

The generous material and moral support of CIDA, DCI, DfID, IDRC, JEAPP, USAID, AUSAID and the NRF is gratefully acknowledged. In addition, those patients in the ART programme who were (and are still) willing to act as respondents in the study are sincerely thanked for sacrificing time and energy, and for frankly sharing views and experiences with the researchers. In similar vain, we wish to acknowledge the management and health care staff of the Free State Department of Health and of several local municipalities, who facilitated this research.

\section{REFERENCES}

Abadía-Barrero, C. and A. Castro: 2006, 'Experiences of stigma and access to HAART in children and adolescents living with HIV/AIDS in Brazil', Social Science \& Medicine 62(5), pp. 1219-1228. 
Alexandrova, A.: 2005, 'Subjective well-being and Kahneman's 'objective happiness”, Journal of Happiness Studies 6, pp. 301-324.

Alubo, O., A. Zwandor, T. Jolayemi and E. Omudu: 2002, 'Acceptance and stigmatisation of PLWA in Nigeria', AIDS Care 14(1), pp. 117-126.

Biswas-Diener, R. and E. Diener: 2001, 'Making the best of a bad situation: satisfaction in the slums of Calcutta', Social Indicators Research 55, pp. 329-352.

Bowling, A.: 2005, Measuring Health: A Review of Quality of Life Measurement Scales (Open University Press, New York).

Brecht, J.R., B. Breitbart, M. Galietta, S Krivo and B. Rosenfeld: 2001, 'The use of highly active antiretroviral therapy (HAART) in patients with advanced HIV infection: Impact on Medical, Palliative Care, and QoL outcomes', Journal of Pain and Symptom Management 21(1), pp. 41-51.

Burgoyne, R. and R. Renwick: 2004, 'Social support and quality of life over time among adults living with HIV in the HAART era', Social Science \& Medicine 58, pp. 1353-1366.

Busza, J.R.: 2001, 'Promoting the positive: responses to stigma and discrimination in Southeast Asia', AIDS Care 13(4), pp. 441-456.

Carrieri, P., B. Spire, S. Duran, C. Katlama, D. Peyramond, C. François, G. Chêne, J.M. Lang, J.P. Moatti and C. Leport, APROCO Study Group: 2003, 'Health-related quality of life after 1 year of highly active antiretroviral therapy', Journal of Acquired Immune Deficiency Syndromes 32(1), pp. 38-47.

Chen, J., M.J. Choe, S. Chen and S. Zhang: 2005, 'Community Environment and HIV/AIDSrelated Stigma in China', AIDS Education and Prevention 17(1), pp. 1-11.

Cleary, S., A. Boulle, D. McIntyre and D. Coetzee: 2004. Cost-effectiveness of antiretroviral treatment for HIV-positive adults in a South African township (Cape Town, Health Systems Trust, MSF and University of Cape Town).

Cobb, M. and T. Chabert: 2002, 'HIV/AIDS and care provider attributions: Who's to blame?', AIDS Care 14(4), pp. 545-548.

Coetzee, D., K. Hildebrand, A. Boulle, G. Maartens, F. Louis, F. Labatala, H. Reuter, N. Ntwana and E. Goemaere: 2004, 'Outcomes after two years of providing antiretroviral treatment in Khayelitsha, South Africa', AIDS 18, pp. 887-895.

Council for Medical Schemes: 2003, Annual report of the Registrar of Medical Schemes 20022003 (Council for Medical Schemes, Pretoria).

Creese, A., K. Floyd, A. Alban and L. Guiness: 2002, 'Cost-effectiveness of HIV/AIDS interventions in Africa: a systematic review of the evidence', The Lancet 359, pp. 1635-1642.

Crook, J., G. Browne, J. Roberts and A. Gafni: 2005, 'Impact of support services provided by a community-based AIDS service organization on persons living with HIV/AIDS', Journal of the Association of Nurses in AIDS Care 16(4), pp. 39-49.

D'Angelo, L.J., S.E. Abdalian, M. Sarr, N. Hoffman and M. Belzer, The Adolescent Medicine HIV/AIDS Research Network: 2001, 'Disclosure of serostatus by HIV infected youth: The experience of the REACH study', Journal of Adolescent Health 29S, pp. 72-79.

Delate, T. and S.J. Coons: 2001, 'The use of 2 health-related quality-of-life measures in a sample of persons infected with human immunodeficiency virus', Clinical Infectious Diseases 32, pp. E47-E52.

Dorrington, R.E., D. Bradshaw, L. Johnson and D. Budlender: 2004, The Demographic Impact of HIV/AIDS in South Africa: National Indicators for 2004 (Centre for Actuarial Research, South African Medical Research Council and Actuarial Society of South Africa, Cape Town).

Drummond, M. and F. Pang: 2001, 'Transferability of economic evaluation results', in M. Drummond and A. McGuire (eds.) Economic Evaluation in Health Care: Merging Theory with Practice, Oxford University Press, Oxford. 
Echteld, M.A., L. Deliens, M.E. Ooms, M.W. Ribbe and G. Wal: 2005, 'Quality of life change and response shift in patients admitted to palliative care units: A pilot study', Palliative Medicine 19, pp. 381-388.

Eriksson, L.E., G. Nordström, T. Berglund and E. Sandström: 2000, 'The health-related quality of life in a Swedish sample of HIV-infected persons', Journal of Advanced Nursing 32(5), pp. 1213-1223.

Essink-Bot, M.L., P.F. Krabbe, G.J. Bonsel and N.K. Aaronson: 1997, 'An empirical comparison of four generic health status measures. The Nottingham Health Profile, the Medical Outcomes Study 36-item Short-Form Health Survey, the COOP/WONCA charts, and the Euroqol instrument', Medical Care 35, pp. 522-537.

Evans, S. and P. Huxley: 2005, 'Adaptation, response-shift and quality of life ratings in mentally well and unwell groups', Quality of Life Research 14(7), pp. 1719-1732.

Forman, L., Y. Pillay and L. Sait: 2004, Health Legislation 1994-2003. South African Health Review 2003/2004 (Health Systems Trust, Durban).

Forsythe, S. and C. Gilks: 1999, 'Economic issues and antiretroviral therapy in developing countries', Transactions of the Royal Society of Tropical Medicine and Hygiene 93, pp. 1-3.

Freedberg, K.A., E. Losina, M. Weinstein, A.D. Paltiel, C.J. Cohen, G.R. Seage, D.E. Craven, H. Zhang, D. April, A.B. Kimmel and S.J. Goldie: 2001, 'The cost effectiveness of combination antiretroviral therapy for HIV disease', New England Journal of Medicine 344(11), pp. 824-831.

Free State Department of Health: 2005, Implementation of the Comprehensive Care, Management and Treatment of HIV and AIDS patients: Outcomes of the first year, 2004 (Free State Department of Health, Bloemfontein).

Free State Department of Health: 2006, Monthly Update on Antiretroviral Treatment Programme (Free State Department of Health, Bloemfontein).

Gielen, A.C., K.A. McDonnell, A.W. Wu, P. O'Campo and R. Faden: 2001, 'Quality of life among women living with HIV: The importance of violence, social support, and self care behaviors', Social Science \& Medicine 52, pp. 315-322.

Hajiran, H.: 2006, 'Toward a quality of life theory: net domestic product of happiness', Social Indicators Research 75, pp. 31-43.

Hughes, J., J. Jelsma, E. Maclean, M. Darder and X. Tinise: 2004, 'The health-related quality of life of people living with HIV/AIDS', Disability and Rehabilitation 26(6), pp. 371-376.

Hurst, N.P., P. Kind, D. Ruta, M. Hunter and A. Stubbings: 1997, 'Measuring health-related quality of life in rheumatoid arthritis: Validity, responsiveness and reliability of EuroQol (EQ-5D)', British Journal of Rheumatology 36, pp. 551-559.

Ijumba, P., C. Poole, G. George and A. Gray: 319 2004, Access to Antiretroviral Therapy. South African Health Review 2003/04 (Health Systems Trust, Durban), pp. 319-338.

Jack, W.: 1999, Principles of Health Economics for Developing Countries (World Bank, Washington, DC).

Jefferson, T., V. Demicheli and M. Mugford: 2000, Elementary Economic Evaluation in Health Care (BMJ Books, London).

Jelsma, J. and G. Ferguson: 2004, 'The determinants of self-reported health-related quality of life in a culturally and socially diverse South African Community', Bulletin of the World Health Organisation 82, pp. 206-212.

Jelsma, J., S. Mkoka, L. Amosun and J. Nieuwveldt: 2004, 'The reliability and validity of the Xhosa version of the EQ-5D', Disability and Rehabilitation 26, pp. 103-108.

Kalichman, S.C. and L. Simbayi: 2004, 'Traditional beliefs about the cause of AIDS and AIDSrelated stigma in South Africa', AIDS Care 16(5), pp. 572-580.

Kim-Prieto, C., E. Diener, M. Tamir, C. Scollon and M. Diener: 2005, 'Integrating the diverse definitions of happiness: A time-sequential framework of subjective well-being', Journal of Happiness Studies 6, pp. 261-300. 
Kind, P., P. Dolan, C. Gudex and A. Williams: 1998, 'Variations in population health status: Results from a United Kingdom national questionnaire survey', British Medical Journal 316, pp. 736-41.

Klein, S.J., W.D. Karchner and D.A. O'Connell: 2002, 'Interventions to prevent HIV-related stigma and discrimination: Findings and recommendations for public health practice', Journal of Public Health Management Practice 8(6), pp. 44-53.

Klitzman, R.L., S.B. Kirshenbaum, B. Dodge, R.H. Remien, A.A. Ehrhardt, M.O. Johnson, L.E. Kittel, S. Daya, S.F. Morin, J. Kelly, M. Lightfoot and M.J. Rotheram-Borus, The NIHM Health Living Trial Group: 2004, 'Intricacies and inter-relationships between HIV disclosure and HAART: A qualitative study', AIDS Care 16(5), pp. 628-640.

Krabbe, P. and T. Weijnen: 2003, 'Guidelines for analysing and reporting EQ-5D outcomes', in R. Brooks, R. Rabin and F. Charrode (eds.) The Measurement and Valuation of Health Status Using EQ-5D: A European Perspective, Kluwer Academic Publishers, Dordrecht, London, pp. 7-19.

Lau, J.T.F., H.Y. Tsui, C.K. Li, R.W.Y. Chung, M.W. Chan and A. Molassiotis: 2003, 'Needs assessment and social environment of people living with HIV/AIDS in Hong Kong', Aids Care 15(5), pp. 699-706.

Laurent, C., C. Kouanfack, S. Koulla-Shiro, N. Nkoué, A. Bourgeois, A. Calmy, B. Lactuock, V. Nzeusseu, R. Mougnutou, G. Peytavin, F. Liégeois, F. Nerrienet, M. Tardy, M. Peeters, I. Andrieux-Meyer, L. Zekeng, M. Kazatchkine, E. Mpoudi-Ngolé and E. Delaporte: 2004, 'Effectiveness and safety of a generic fixed-dose combination of nevirapine, stavudine, and lamivudine in HIV-1-infected adults in Cameroon: Open-label multicentre trial', The Lancet 364, pp. 29-34.

Lavalle, C., J.C.D. Aguilar, F. Peña, J.L. Estrada-Aguilar, J.A. Aviña-Zubieta and M. Madrazo: 2000, 'Reduction in hospitalization costs, morbidity, disability, and mortality in patients with AIDS treated with protease inhibitors', Archives of Medical Research 31, pp. 515-519.

Louwagie, G., K. Meyer, M. Bachmann, F. le R. Booysen, L. Fairall and C. Heunis: 2006. 'Health-related Quality of Life in patients selected for antiretroviral treatment in a South African Province: A cross-sectional analytical study', Mimeo. Bloemfontein, University of the Free State.

Makoae, L.N., S.M. Seboni, K. Molosiwa, M. Moleko, S. Human, N.A. Sukati and W.L. Holzemer: 2005, 'The symptom experience of people living with HIV/AIDS in Southern Africa', Journal of the Association of Nurses in AIDS Care 16(3), pp. 22-32.

Marseille, E., P.B. Hoffman and J.G. Kahn: 2002, 'HIV prevention before HAART in subSaharan Africa', The Lancet 359, pp. 1851-1856.

Messeri, P.A., D.M. Abramson, A.A. Aidala, F. Lee and G. Lee: 2002, 'The impact of ancillary HIV services on engagement in medical care in New York City', AIDS Care 14 (Supplement 1), pp. S15-S29.

Michalos, A.C.: 2004, 'Social indicators research and health-related quality of life research', Social Indicators Research 65, pp. 27-72.

Miners, A.H., C.A. Sabin, P. Trueman, M. Youle, A. Mocroft, M. Johnson and E.J. Beck: 2001, 'Assessing the cost-effectiveness of highly active antiretroviral therapy for adults with HIV in England', HIV Medicine 2, pp. 52-58.

Møller, V.: 1998, 'Quality of life in South Africa: Post-apartheid trends', Social Indicators Research 43(1), pp. 27-68.

Møller, V.: 1999, 'South African quality of life trends in the late 1990s: Major divides in perceptions', Society in Transition 30(2), pp. 93-105.

Møller, V. and H. Dickow: 2002, 'The role of quality of life surveys in managing change in democratic transitions: The South African case', Social Indicators Research 58(3), pp. 267 292. 
Møller, V. and L. Schlemmer: 1983, 'Quality of life in South Africa: Towards an instrument for the assessment of quality of life and basic needs', Social Indicators Research 12(3), pp. 225279.

Moore, R.D.: 2000, 'Cost effectiveness of combination HIV therapy: 3 years later', Pharmacoeconomics 17(4), pp. 325-330.

Murri, R., M. Fantoni, C. Borgo, R. Visona, A. Barracco, A. Zambelli, L. Testa, N. Orchi, V. Tozzi, O. Bosco and A.W. Wu: 2003, 'Determinants of health-related quality of life in HIV-infected patients', AIDS Care 15(4), pp. 581-590.

National Department of Health: 2003, Operational Plan for Comprehensive HIV and AIDS Care, Management and Treatment for South Africa (National Department of Health, Pretoria).

National Department of Health: 2004, National Antiretroviral Treatment Guidelines (National Department of Health, Pretoria).

Ogden, J. and L. Nyblade: 2005, Common at its Core: HIV-Related Stigma Across Contexts (International Centre for Research on Women, Washington, DC).

Paxton, S.: 2002, 'The paradox of public HIV disclosure', AIDS Care 14(4), pp. 559-567.

Paxton, S., G. Gonzales, K. Uppakaew, K.K. Abraham, S. Okta, C. Green, K.S. Nair, T. Parwati-Merati, B. Thephthien, M. Marin and A. Quesada: 2005, 'Aids-related discrimination in Asia', AIDS Care 17(4), pp. 413-424.

Pearmain, D.: 2000, Impact of Changes to the Medical Schemes Act. South African Health Review 2000 (Health Systems Trust, Durban).

Poundstone, K.E., S.A. Strathdee and D.D. Celentano: 2004, 'The social epidemiology of human immunodeficiency virus/acquired immunodeficiency syndrome', Epidemiologic Reviews 26 , pp. 22-35.

Préau, M., C. Leport, D. Salmon-Ceron, P. Carrieri, H. Portier, G. Chene, B. Spire, P. Choutet, F. Raffi and M. Morin, The APROCO Study Group: 2004, 'Health-related quality of life and patient-provider relationships in HIV-infected patients during the first 3 years after starting PI-containing antiretroviral treatment', AIDS Care 16(5), pp. 649-661.

Reidpath, D.D. and K.Y. Chan: 2005, 'A method for the quantitative analysis of the layering of HIV-related stigma', AIDS Care 17(4), pp. 425-432.

Sendi, P.P., H.C. Bucher, T. Harr, B.A. Craig, M. Schwietert, D. Pfluger, A. Gafni and M. Battegay: 1999, 'Cost effectiveness of highly active antiretroviral therapy in HIV-infected patients', AIDS 13, pp. 1115-1122.

Sendi, P., F. Schellenberg, C. Ungsedhapand, G.R. Kaufmann, H.C. Bucher, R. Weber and M. Battegay, Swiss HIV Cohort Study: 2004, 'Productivity costs and determinants of productivity in HIV-infected patients', Clinical Therapeutics 26(5), pp. 791-800.

Siegel, K. and E.W. Schrimshaw: 2005, 'Stress, appraisal, and coping: A comparison of HIVinfected women in the pre-HAART and HAART eras', Journal of Psychosomatic Research 58 , pp. 225-233.

Stein, A., H. McLeod and Z. Achmat: 2002. The cover provided for HIV/AIDS benefits in medical schemes in 2002. CARE Monograph No. 10. University of Cape Town: Centre for Actuarial Research.

Stewart, K.E., L.R. Cianfrini and J.F. Walker: 2005, 'Stress, social support and housing are related to health status among HIV-positive persons in the Deep South of the United States', AIDS Care 17(3), pp. 350-358.

Stewart, R. and M. Loveday: 2005, The Operation Plan: Implementation of the Antiretroviral Therapy Component. South African Health Review 2005 (Health Systems Trust, Durban).

Sugimoto, N., M. Ichikawa, B. Siriliang, S. Nakahara, M. Jimba and S. Wakai: 2005, 'Herbal medicine use and quality of life among people living with HIV/AIDS in northeastern Thailand', AIDS Care 17(2), pp. 252-262.

Teixeira, P.R., M.A. Vitoria and J. Barcarolo: 2004, 'Antiretroviral treatment in resource-poor settings: the Brazilian experience', AIDS 18(3), pp. S5-S7. 
The EuroQol Group: 1990, 'EuroQol - a new facility for the measurement of health-related quality of life', Health Policy 16, pp. 199-208.

Tramarin, A., S. Campostrini, M.J. Postma, G. Calleri, K. Tolley, N. Parise and F. Lalla: 2004, 'A multicentre study of patient survival, disability, quality of life and cost of care among patients with AIDS in Northern Italy', Pharmacoeconomics 22(1), pp. 43-53.

Van Praag, B.M.S. and A. Ferrer-I-Carbonell: 2004, Happiness Quantified: A Satisfaction Calculus Approach (Oxford University Press, New York).

Veenhoven, R.: 2000, 'The four qualities of life: ordering concepts and measures of the good life', Journal of Happiness Studies 1, pp. 1-39.

Weidle, P.J., S. Malamba, R. Mwebaze, C. Sozi, G. Rukundo, R. Downing and D. Hanson: 2002, 'Assessment of a pilot antiretroviral drug therapy programme in Uganda: Patients' response, survival, and drug resistance', The Lancet 360, pp. 34-40.

Williams, P., L. Narciso, G. Browne, J. Roberts, R. Weir and A. Gafni: 2005, 'Characteristics of people living with HIV who use community-based services in Ontario, Canada: Implications for service providers', Journal of the Association of Nurses in AIDS Care 16(4), pp. 50-63.

WHO: 2005, "3 $\times 5$ " Progress Report (WHO and UNAIDS, Geneva).

Wood, E., P. Braitstein, J.S.G. Montaner, M.T. Schechter, M.W. Tyndall, M.V. O'Shaughnessy and R.S. Hogg: 2000, 'Extent to which low-level use of antiretroviral treatment could curb the AIDS epidemic in sub-Saharan Africa', The Lancet 355, pp. 2095-100.

Wu, A.W., K.L. Jacobson, K.D. Frick, R. Clark, D.A. Revicki, K.A. Freedberg, J. ScottLennox and J. Feinberg: 2002, 'Validity and responsiveness of the Euroqol as a measure of health-related quality of life in people enrolled in an AIDS clinical trial', Quality of Life Research 11, pp. 273-82.

Centre for Health Systems Research \& Development

University of the Free State

BoOysen F LE R

339 Bloemfontein, 9300,

South Africa

E-mail: Booyensenf.ekw@mail.uovs.ac.za

School of Medicine, Health Policy and Practice

BACHMANN M

University of East Anglia

Norwich, NR4 7TJ, UK

Department of Community Health, Faculty of Medicine

Louwagie G

University of the Free State

339 Bloemfontein, 9300,

South Africa

Cape Town Lung Institute, Department of Medicine

FAIRALL L

University of Cape Town

Observatory, 7925,

South Africa 